Research Article

\title{
One-Dimensional Large-Strain Nonlinear Consolidation of Overconsolidated Clays with a Threshold Hydraulic Gradient
}

\author{
Chuanxun Li $\mathbb{D}^{1},{ }^{1}$ Jinyang Xiao $\mathbb{D}^{1},{ }^{1}$ Yang Yang $\left(\mathbb{D},{ }^{1}\right.$ and Wenbing Wu $\mathbb{D}^{2}$ \\ ${ }^{1}$ Faculty of Civil Engineering and Mechanics, Jiangsu University, Zhenjiang 212013, China \\ ${ }^{2}$ Engineering Research Center of Rock Soil Drilling \& Excavation and Protection, Ministry of Education, \\ China University of Geosciences, Wuhan 430074, China \\ Correspondence should be addressed to Chuanxun Li; lichuanxun@yeah.net
}

Received 28 May 2018; Accepted 15 November 2018; Published 13 December 2018

Academic Editor: Arnaud Perrot

Copyright ( $\odot 2018$ Chuanxun Li et al. This is an open access article distributed under the Creative Commons Attribution License, which permits unrestricted use, distribution, and reproduction in any medium, provided the original work is properly cited.

\begin{abstract}
The existence of the threshold hydraulic gradient in clays under a low hydraulic gradient has been recognized by many studies. Meanwhile, most nature clays to some extent exist in an overconsolidated state more or less. However, the consolidation theory of overconsolidated clays with the threshold hydraulic gradient has been rarely reported in the literature. In this paper, a onedimensional large-strain consolidation model of overconsolidated clays with consideration of the threshold hydraulic gradient is developed, and the finite differential method is adopted to obtain solutions for this model. The influence of the threshold hydraulic gradient and the preconsolidation pressure of overconsolidated clay on consolidation behavior is investigated. The consolidation rate under large-strain supposition is faster than that under small-strain supposition, and the difference in the consolidation rate between different geometric suppositions increases with an increase in the threshold hydraulic gradient and a decrease in the preconsolidation pressure. If Darcy's law is valid, the final settlement of overconsolidated clays under large-strain supposition is the same as that under small-strain supposition. For the existence of the threshold hydraulic gradient, the final settlement of the clay layer with large-strain supposition is greater than that with small-strain supposition.
\end{abstract}

\section{Introduction}

The clay whose present effective overburden stress is equal to that in the nature state is called normally consolidated clay. Normally consolidated clays are usually found in young geological deposits or prepared resedimented samples in the laboratory. The clay whose present effective overburden stress is less than that in the nature state is called overconsolidated clay. In practice, most nature clays to some extent exist in an overconsolidated state more or less. There are some differences in consolidation parameters between normally consolidated and overconsolidated clays. The coefficient of volume compressibility $\left(m_{\mathrm{v}}\right)$ of overconsolidated clays is smaller than that of normally consolidated clays corresponding to the same pressure, for instance, and the coefficient of consolidation $\left(c_{\mathrm{v}}\right)$ of overconsolidated clays may be larger than that of normally consolidated clays corresponding to the same pressure. Therefore, there has been some progress in the theory of consolidation of clays with consideration of the overconsolidated state $[1-3]$. These studies show that the overconsolidated state certainly has great influences on consolidation behavior.

The estimation of settlement is fundamental to all the designs of civil structures [4]. The consolidation theory of clays, which reveals the constitutive relationship of the deformation and the dissipation of excess pore water pressure, plays a vital role in the calculation of the settlement of clays [5-7]. The consolidation also has great influences on the temporal and spatial variation of clay properties [8]. Therefore, since Terzaghi's theory of consolidation was developed [9], the theory of consolidation is one of the most important theories in geomechanics. Darcy's law is usually adopted to describe the water flow in these theories of consolidation. For fine-grained overconsolidated clays under low hydraulic gradients, however, the deviation of water flow from Darcy's law has been confirmed in some studies [10-14]. The water flow obeying Darcy's law is usually called 
as the Darcian flow, while the water flow in clays deviating from Darcy's law may be named as the non-Darcian flow. The model of the water flow in clays with a threshold gradient [11] is the simplest one in these non-Darcian flow laws. The existence of the threshold gradient in an absolute sense still is a controversy. However, just like the reasonable presentation [15], the effective permeability of the clay with other non-Darcian flows may decrease rather abruptly under low gradient. Under this condition, an approximation to the effective flow velocity described by non-Darcian flow $[10,13]$ can be provided by the model of water flow in clay with a threshold gradient. In this way, there has been some progress in consolidation theories of clays with a threshold gradient [16-20]. The small-strain supposition was incorporated in all above consolidation theories with consideration of a threshold gradient, while the characteristics of large strain and overconsolidated state in nature soft clays were also ignored in these theories.

Since the governing equation of one-dimensional largestrain consolidation was developed [21], in which the void ratio of clay was adopted as a variable, several studies have been developed on the theory of large-strain consolidation in numerical and analytical methods [22-26]. However, all these studies on one-dimensional large-strain consolidation essentially based on Darcy's law may not be applicable to fine-grained overconsolidated clays under low gradients. As stated above, for fine-grained clays, there is a theoretical significance in large-strain consolidation theory with consideration of a threshold gradient.

The main objective of this paper is to develop a new model for one-dimensional large-strain consolidation of overconsolidated clays with a threshold hydraulic gradient. Moreover, the influences of the threshold hydraulic gradient and overconsolidated state on large-strain consolidation behavior will be analyzed.

\section{Effective Stress, Compressibility, and Permeability of Overconsolidated Clays}

As shown in Figure 1, the initial thickness of the clay layer is $H$. The bottom of the clay layer is fixed and referenced to the Lagrangian coordinate system. The Lagrangian coordinate $a$ is measured downwards in the direction of gravity. The top surface of the layer $(a=0)$ is pervious, and the bottom surface $(a=H)$ is impervious. The current vertical effective stress at Lagrangian coordinate $a$ resulting from the self-weight stress of the clay layer is labeled as $\sigma_{\mathrm{v} 0}^{\prime}(a)$. The vertical preconsolidation stress, $\sigma_{\mathrm{vpc}}^{\prime}(a)$, is defined as the maximum vertical effective stress experienced by the overconsolidated clay layer. For overconsolidated clays, the current vertical effective stress must be less than the vertical preconsolidation stress, and the reduction in vertical effective stress could have resulted from melting of ice sheets, erosion of overburden pressure, or a rise in the water table. The relationship between $\sigma_{\mathrm{vpc}}^{\prime}$ and $\sigma_{\mathrm{v} 0}^{\prime}$ in the Lagrangian coordinate is as follows:

$$
\sigma_{\mathrm{vpc}}^{\prime}(a)=\sigma_{\mathrm{v} 0}^{\prime}(a)+\sigma_{\mathrm{pc}},
$$

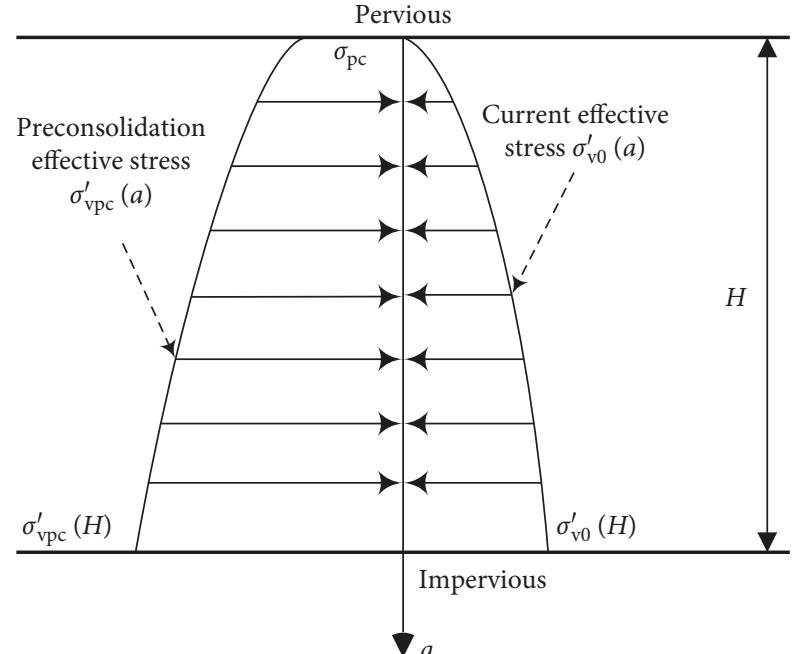

Figure 1: An overconsolidated clay layer.

where $\sigma_{\mathrm{pc}}$ is the reduction in vertical effective stress for an overconsolidated clay layer at the same Lagrangian coordinate. It is usually supposed to be constant with depth.

The relationship between the void ratio $(e)$ and the vertical effective stress of overconsolidated clays $\left(\sigma_{\mathrm{v}}^{\prime}\right)$ is shown as a semi-log plot in Figure 2. AP and PB in Figure 2 correspond to the normal compression line in the curve of $e-\log \sigma_{\mathrm{v}}^{\prime}$, and the normal compression line can be expressed as follows:

$$
e-e_{1}=C_{\mathrm{c}} \log \frac{\sigma_{\mathrm{v} 1}^{\prime}}{\sigma_{\mathrm{v}}^{\prime}}
$$

where $\sigma_{\mathrm{v} 1}^{\prime}$ is a given vertical effective stress on the normal compression line of clays; $e_{1}$ is the void ratio corresponding to the vertical effective stress $\sigma_{\mathrm{v} 1}^{\prime}$ on the normal compression line; and $C_{c}$ is called as the compression index, and it is the slope of the normal compression line. If the vertical effective stress $\sigma_{\mathrm{v}}^{\prime}$ reduces at point $\mathrm{P}$ to the current vertical stress $\sigma_{\mathrm{v} 0}^{\prime}$ for some reason, DP corresponds to the unloading and reloading line of the overconsolidated clay. Upon reloading beyond $\mathrm{P}$, the overconsolidated clay continues along the path that it would have followed if loaded from A to B continuously. The vertical effective stress at point $\mathrm{P}$ of the normal compression line is called as preconsolidation stress. The preconsolidation stress, $\sigma_{\mathrm{vpc}}^{\prime}$, and the corresponding void ratio, $e_{\mathrm{pc}}$, can be expressed as follows:

$$
e_{\mathrm{pc}}-e_{1}=C_{\mathrm{c}} \log \left(\frac{\sigma_{\mathrm{v} 1}^{\prime}}{\sigma_{\mathrm{vpc}}^{\prime}}\right) .
$$

The initial void ratio of the overconsolidated clay, $e_{0}$, which corresponds to $\sigma_{\mathrm{v} 0}^{\prime}$, is as follows:

$$
e_{0}-e_{\mathrm{pc}}=C_{\mathrm{r}} \log \left(\frac{\sigma_{\mathrm{vpc}}^{\prime}}{\sigma_{\mathrm{v} 0}^{\prime}}\right) \text {. }
$$

The relationship between $e$ and $\sigma^{\prime}$ for overconsolidated clays obeys the following equations: 


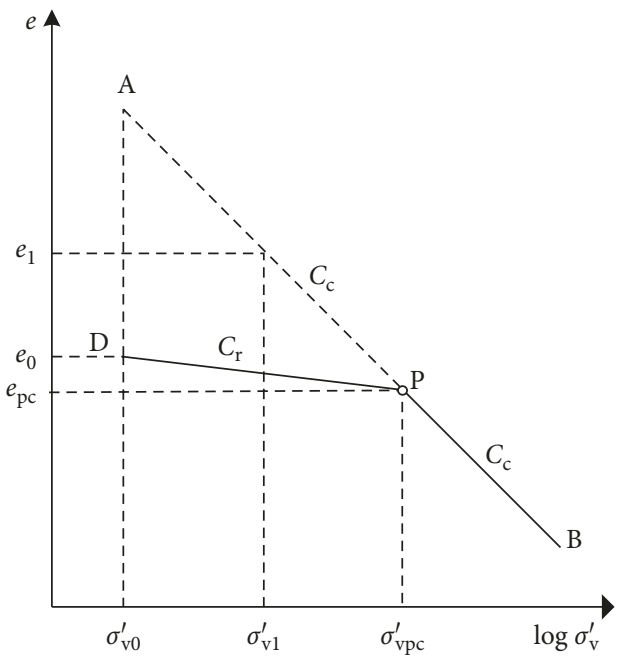

Figure 2: The relationship between $e$ and $\sigma_{\mathrm{v}}^{\prime}$ of overconsolidated clays.

$$
\begin{aligned}
& e-e_{1}=C_{\mathrm{c}} \log \left(\frac{\sigma_{\mathrm{v} 1}^{\prime}}{\sigma_{\mathrm{v}}^{\prime}}\right), \quad \sigma_{\mathrm{v}}^{\prime} \geq \sigma_{\mathrm{vpc}}^{\prime}, \\
& e-e_{\mathrm{pc}}=C_{\mathrm{r}} \log \left(\frac{\sigma_{\mathrm{vpc}}^{\prime}}{\sigma_{\mathrm{v}}^{\prime}}\right), \quad \sigma_{\mathrm{v} 0}^{\prime} \leq \sigma_{\mathrm{v}}^{\prime}<\sigma_{\mathrm{vpc}}^{\prime},
\end{aligned}
$$

where $C_{\mathrm{r}}$ is called as the recompression index, and it is equal to the slope of the recompression line $\left(e-\log \sigma^{\prime}\right)$ of overconsolidated clay from $\sigma_{\mathrm{v} 0}^{\prime}$ to $\sigma_{\mathrm{vpc}}^{\prime}$. If the influence of sedimentation on $\sigma_{\mathrm{v} 0}^{\prime}(a)$ is considered, $\sigma_{\mathrm{v} 0}^{\prime}(a)$ at Lagrangian coordinate $a$ can be calculated by the following integration [27]:

$$
\sigma_{\mathrm{v} 0}^{\prime}(a)=\int_{0}^{a} \frac{\gamma_{\mathrm{w}}\left(G_{\mathrm{s}}-1\right)}{1+e_{0}} d a,
$$

where $G_{\mathrm{s}}$ is the specific gravity of clay particles and $\gamma_{\mathrm{w}}$ is the unit weight of water. By substituting equation (2) into equation (7), $\sigma_{\mathrm{v} 0}^{\prime}(a)$ can further be expressed as follows:

$$
\begin{aligned}
(1 & \left.+e_{1}+0.4343 C_{\mathrm{c}}\right) \sigma_{\mathrm{v} 0}^{\prime}(a)-C_{\mathrm{c}} \sigma_{\mathrm{v} 0}^{\prime}(a) \log \left[\frac{\sigma_{\mathrm{v} 0}^{\prime}(a)}{\sigma_{\mathrm{v} 1}^{\prime}}\right] \\
& =\gamma_{\mathrm{w}}\left(G_{\mathrm{s}}-1\right) a .
\end{aligned}
$$

It can be found that the initial effective stress in clay does not increase linearly with depth when sedimentation of the deposit is considered. If $\sigma_{\mathrm{pc}}$ is given, the preconsolidation stress $\sigma_{\mathrm{vpc}}^{\prime}$ of an overconsolidated clay can also be determined by equations (1) and (8).

The water flow in the clay is assumed to obey the flow model with a threshold gradient, and this model can be expressed as follows:

$$
v= \begin{cases}0, & i<i_{0}, \\ k_{\mathrm{v}} i\left(1-\frac{i_{0}}{i}\right), & i \geq i_{0},\end{cases}
$$

where $v$ is the velocity of water flow in clays; $i$ is the hydraulic gradient; $k_{\mathrm{v}}$ is the coefficient of vertical permeability; and $i_{0}$ is the threshold hydraulic gradient, and the value is supposed to be constant during the consolidation. Equation (9) is reduced to Darcy's law when $i_{0}=0$ but yields a form of non-Darcian flow when $i_{0} \neq 0$. The following well-known logarithmic relation $\left(e-\log k_{\mathrm{v}}\right)$ is used to describe the nonlinear variations of coefficient of permeability during consolidation [2]:

$$
e=e_{1}+C_{\mathrm{k}} \log \left(\frac{k_{\mathrm{v}}}{k_{\mathrm{v} 1}}\right),
$$

where $C_{\mathrm{k}}$ is the permeability index, and it is equal to the slope of an $e-\log k_{\mathrm{v}}$ curve, and $k_{\mathrm{v} 1}$ is the coefficient of permeability corresponding to the given void ratio $e_{1}$.

\section{Analysis of Moving Boundary}

As shown in Figure 3, the clay layer subjects to a timedependent uniform load $q(t)$ on the top surface. The ultimate magnitude and the time of establishment for the timedependent load are labeled as $q_{c}$ and $t_{c}$, respectively. The initial value of time-dependent load is labeled as $q_{0}$. As indicated by the dotted line in Figure 4, a ramp load is a special case of time-dependent load. If the time-dependent load is applied at the top surface over a very large area, the excess pore water pressure in the clay layer, $u$, will increase at all depths of the clay layer, and the increase in $u$ will be equal to the increase of the external load. In this way, the water in the void spaces of the clay layer will be squeezed out and flow toward the pervious surface. If a threshold hydraulic gradient in water flow exists, there will be no water flow and $u$ will not dissipate for the region of the clay layer in which $i \leq i_{0}$. Only for the region of the clay layer in which $i>i_{0}$, there is water flow in the clay and $u$ gradually dissipates with time. An existing boundary between the two regions is named as the flow front. Furthermore, the flow front moves from the top of the clay down with the dissipation of excess pore water pressure during the consolidation. When the flow front does not reach the bottom of the clay layer, the problem of consolidation with the threshold gradient consequently becomes a moving boundary problem as illustrated in Figure 3. The Lagrangian coordinate of the flow front at time $t$ is noted as $h(t)$. According to the studies $[16,17]$, the gradient of excess 


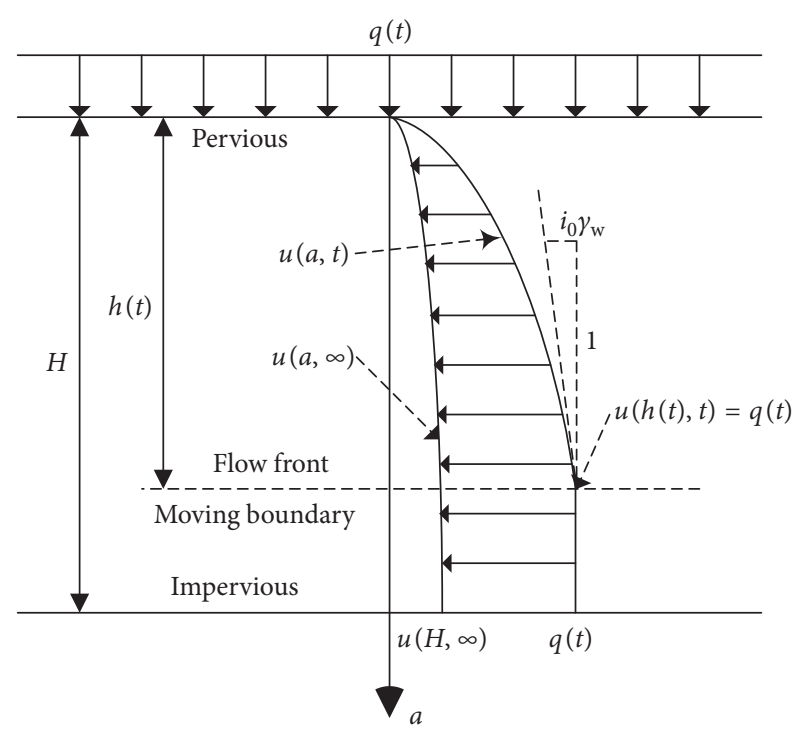

FIGURE 3: Analysis of moving boundary in the Lagrangian coordinate.

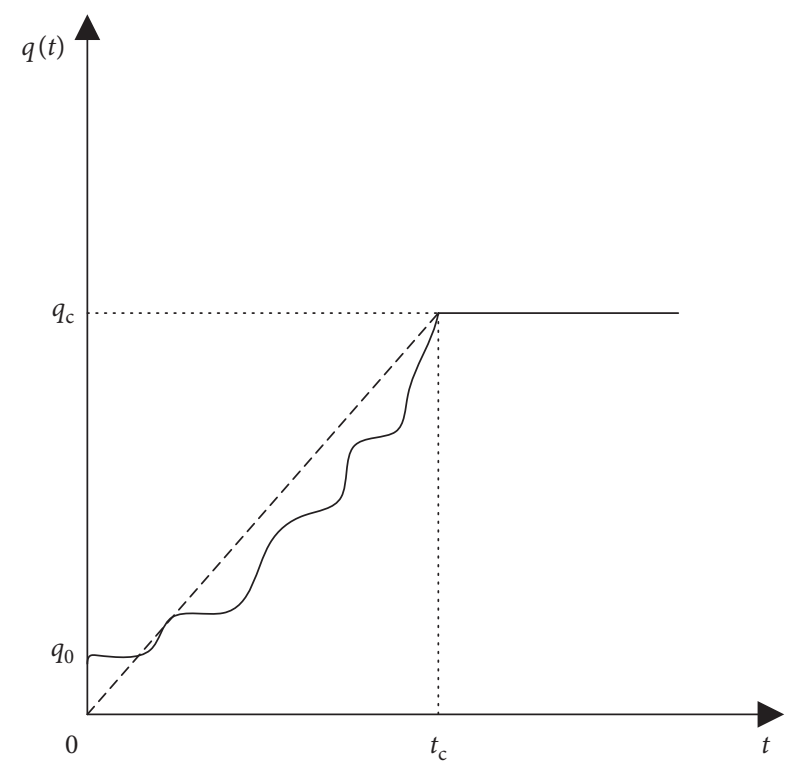

Figure 4: Time-dependent load.

pore water pressure and the excess pore water pressure at the moving boundary $(a=h(t))$ are as follows:

$$
\begin{gathered}
u[h(t), t]=q(t), \\
\left.i\right|_{a=h(t)}=i_{0} .
\end{gathered}
$$

For the existence of the threshold gradient, the excess pore water pressure cannot dissipate completely at the end of consolidation. The final residual value of excess pore water pressure at Lagrangian coordinate $a$ is noted as $u(a, \infty)$. If $u(H, \infty)<q_{c}$, it means that the moving boundary can reach the bottom of the clay layer. If the excess pore water pressure at the impervious surface is constant during the whole progress of consolidation, on the contrary, the moving boundary cannot reach the bottom of the clay layer.

\section{The Mathematical Model: Governing Equations and Solution Conditions}

Based on the study by Xie and Leo [26], the hydraulic gradients $i$ can be expressed in the Lagrangian coordinate as follows:

$$
i=\frac{1}{\gamma_{\mathrm{w}}} \frac{1+e_{0}}{1+e} \frac{\partial u}{\partial a},
$$

where $e$ is the void ratio which varies with Lagrangian coordinate $a$ and time $t$. With consideration of the incompressibility of clay particles and pore water, according to the study by Xie and Leo [26], the general continuity condition for one-dimensional large-strain consolidation in the Lagrangian coordinate can be given as follows:

$$
\frac{\partial v}{\partial a}=-\frac{1}{1+e_{0}} \frac{\partial e}{\partial t},
$$

where $t$ is the time. If the creep effect of the clay skeleton is ignored and the consolidation is assumed to be monotonic, the void ratio $e$ is solely dependent on the effective stress $\sigma_{\mathrm{v}}^{\prime}$, and then equation (14) can be rewritten as follows:

$$
\frac{\partial v}{\partial a}=-\frac{1}{1+e_{0}} \frac{\partial e}{\partial \sigma_{\mathrm{v}}^{\prime}} \frac{\partial \sigma_{\mathrm{v}}^{\prime}}{\partial t}
$$

According to the theory of effective stress, the effective stress $\sigma_{v}^{\prime}$ at time $t$ can be expressed as follows:

$$
\sigma_{\mathrm{v}}^{\prime}(a, t)=q(t)+\sigma_{\mathrm{v} 0}^{\prime}(a, t)-u(a, t) .
$$

Substituting equations (9), (13), and (16) into equation (15), the following equation can be obtained:

$$
\begin{aligned}
u & =q(t), \quad \frac{1+e_{0}}{1+e} \frac{1}{\gamma_{\mathrm{w}}} \frac{\partial u}{\partial a}<i_{0}, \\
\frac{\partial}{\partial a} & {\left[\frac{k_{\mathrm{v}}}{\gamma_{\mathrm{w}}} \frac{1+e_{0}}{1+e}\left(1-\frac{i_{0}}{\left(1 / \gamma_{\mathrm{w}}\right)\left(\left(1+e_{0}\right) /(1+e)\right)(\partial u / \partial a)}\right) \frac{\partial u}{\partial a}\right] } \\
& =\frac{1}{1+e_{0}} \frac{\partial e}{\partial \sigma^{\prime}}\left(\frac{d q}{d t}-\frac{\partial u}{\partial t}\right), \quad \frac{1}{\gamma_{\mathrm{w}}} \frac{1+e_{0}}{1+e} \frac{\partial u}{\partial a} \geq i_{0} .
\end{aligned}
$$

With equations (5), (6), and (10), the coefficient of permeability and the coefficient of compressibility of overconsolidated clays change with the effective stress as follows:

$$
\begin{aligned}
& \frac{d e}{d \sigma_{\mathrm{v}}^{\prime}}= \begin{cases}-\frac{C_{\mathrm{r}}}{\sigma_{\mathrm{v}}^{\prime} \ln 10}, & \sigma_{\mathrm{v} 0}^{\prime} \leq \sigma_{\mathrm{v}}^{\prime} \leq \sigma_{\mathrm{vpc}}^{\prime}, \\
-\frac{C_{\mathrm{c}}}{\sigma_{\mathrm{v}}^{\prime} \ln 10}, & \sigma_{\mathrm{v}}^{\prime}>\sigma_{\mathrm{vpc}}^{\prime},\end{cases} \\
& k_{\mathrm{v}}= \begin{cases}k_{\mathrm{v} 1}\left(\frac{\sigma_{\mathrm{v} 1}^{\prime}}{\sigma_{\mathrm{vpc}}^{\prime}}\right)^{C_{\mathrm{c}} / C_{\mathrm{k}}}\left(\frac{\sigma_{\mathrm{vpc}}^{\prime}}{\sigma_{\mathrm{v}}^{\prime}}\right)^{C_{\mathrm{r}} / C_{\mathrm{k}}}, \sigma_{\mathrm{v} 0}^{\prime} \leq \sigma_{\mathrm{v}}^{\prime} \leq \sigma_{\mathrm{vpc}}^{\prime}, \\
k_{\mathrm{v} 1}\left(\frac{\sigma_{\mathrm{v} 1}^{\prime}}{\sigma_{\mathrm{v}}^{\prime}}\right)^{C_{\mathrm{c}} / C_{\mathrm{k}}}, & \sigma_{\mathrm{v}}^{\prime}>\sigma_{\mathrm{vpc}}^{\prime} .\end{cases}
\end{aligned}
$$


Substituting equations (19) and (20) into equation (18), the governing equation for one-dimensional large-strain consolidation of overconsolidated clays with a threshold gradient in the Lagrangian coordinate can be derived as follows:

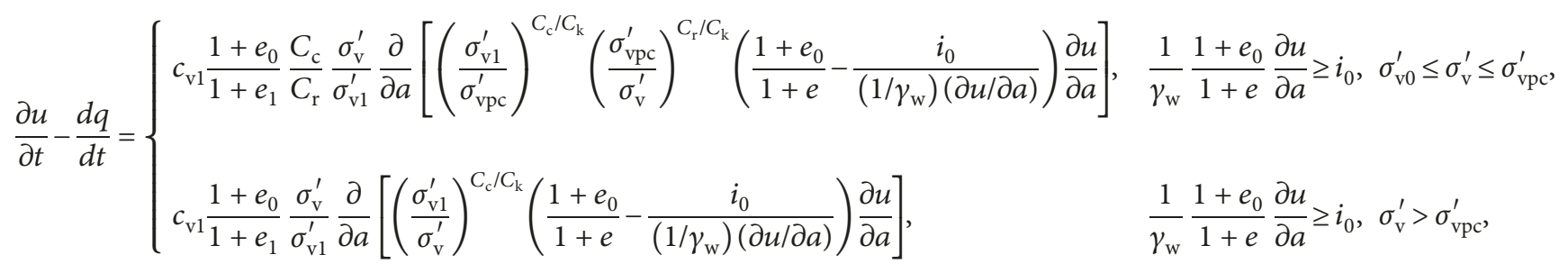

where $c_{\mathrm{v} 1}$ is the coefficient of consolidation corresponding to the given effective stress $\sigma_{\mathrm{vl}}^{\prime}$, and it can be determined by $c_{\mathrm{v} 1}=\sigma_{\mathrm{v} 1}^{\prime}\left(1+e_{1}\right) k_{v 1} \ln 10 /\left(\gamma_{\mathrm{w}} c_{\mathrm{c}}\right)$. In form of $h(t)$, the governing equation for large-strain consolidation of overconsolidated clays with a threshold gradient can be rewritten as follows:

$$
\frac{\partial u}{\partial t}-\frac{d q}{d t}= \begin{cases}c_{\mathrm{v} 1} \frac{1+e_{0}}{1+e_{1}} \frac{C_{\mathrm{c}}}{C_{\mathrm{r}}} \frac{\sigma_{\mathrm{v}}^{\prime}}{\sigma_{\mathrm{v} 1}^{\prime}} \frac{\partial}{\partial a}\left[\left(\frac{\sigma_{\mathrm{v} 1}^{\prime}}{\sigma_{\mathrm{vpc}}^{\prime}}\right)^{C_{\mathrm{c}} / C_{\mathrm{k}}}\left(\frac{\sigma_{\mathrm{vpc}}^{\prime}}{\sigma_{\mathrm{v}}^{\prime}}\right)^{C_{\mathrm{r}} / C_{\mathrm{k}}}\left(\frac{1+e_{0}}{1+e}-\frac{i_{0}}{\left(1 / \gamma_{\mathrm{v}}\right)(\partial u / \partial a)}\right) \frac{\partial u}{\partial a}\right], & 0<a \leq h(t), \sigma_{\mathrm{v} 0 \leq \sigma_{\mathrm{v}}^{\prime} \leq \sigma_{\mathrm{vpc}}^{\prime}} \\ c_{\mathrm{v} 1} \frac{1+e_{0}}{1+e_{1}} \frac{\sigma_{\mathrm{v}}^{\prime}}{\sigma_{\mathrm{v} 1}^{\prime}} \frac{\partial}{\partial a}\left[\left(\frac{\sigma_{\mathrm{v} 1}^{\prime}}{\sigma_{\mathrm{v}}^{\prime}}\right)^{C_{\mathrm{c}} / C_{\mathrm{k}}}\left(\frac{1+e_{0}}{1+e}-\frac{i_{0}}{\left(1 / \gamma_{\mathrm{w}}\right)(\partial u / \partial a)}\right) \frac{\partial u}{\partial a}\right], & 0<a \leq h(t), \sigma_{\mathrm{v}}^{\prime}>\sigma_{\mathrm{vpc}}^{\prime},\end{cases}
$$

$$
\begin{aligned}
& u=q(t), \\
& a>h(t) .
\end{aligned}
$$

When the moving boundary does not reach the bottom of the clay layer, the top boundary condition and the moving boundary condition described by equations (11) and (12) can be expressed as follows:

$$
\begin{gathered}
u(0, t)=0, \\
u[h(t), t]=q(t),
\end{gathered}
$$

$$
\left.\frac{1}{\gamma_{\mathrm{w}}} \frac{1+e_{0}}{1+e} \frac{\partial u}{\partial a}\right|_{a=h(t)}=i_{0} .
$$

The initial condition for this model is as follows:

$$
u(a, 0)=q(0)=q_{0} .
$$

If the moving flow front reaches the bottom of the overconsolidated clay layer, the moving boundary becomes a fixed boundary, and the governing equation for large-strain consolidation of overconsolidated clays with a threshold gradient is as follows:

$$
\frac{\partial u}{\partial t}-\frac{d q}{d t}= \begin{cases}c_{\mathrm{v} 1} \frac{1+e_{0}}{1+e_{1}} \frac{C_{\mathrm{c}}}{C_{\mathrm{r}}} \frac{\sigma_{\mathrm{v}}^{\prime}}{\sigma_{\mathrm{v} 1}^{\prime}} \frac{\partial}{\partial a}\left[\left(\frac{\sigma_{\mathrm{v} 1}^{\prime}}{\sigma_{\mathrm{vpc}}^{\prime}}\right)^{C_{\mathrm{c}} / C_{\mathrm{k}}}\left(\frac{\sigma_{\mathrm{vpc}}^{\prime}}{\sigma_{\mathrm{v}}^{\prime}}\right)^{C_{\mathrm{r}} / C_{\mathrm{k}}}\left(\frac{1+e_{0}}{1+e}-\frac{i_{0}}{\left(1 / \gamma_{\mathrm{v}}\right)(\partial u / \partial a)}\right) \frac{\partial u}{\partial a}\right], \quad 0<a \leq H, \sigma_{\mathrm{v} 0}^{\prime} \leq \sigma_{\mathrm{v}}^{\prime} \leq \sigma_{\mathrm{vpc}}^{\prime} \\ c_{\mathrm{v} 1} \frac{1+e_{0}}{1+e_{1}} \frac{\sigma_{\mathrm{v}}^{\prime}}{\sigma_{\mathrm{v} 1}^{\prime}} \frac{\partial}{\partial a}\left[\left(\frac{\sigma_{\mathrm{v} 1}^{\prime}}{\sigma_{\mathrm{v}}^{\prime}}\right)^{C_{\mathrm{c}} / C_{\mathrm{k}}}\left(\frac{1+e_{0}}{1+e}-\frac{i_{0}}{\left(1 / \gamma_{\mathrm{w}}\right)(\partial u / \partial a)}\right) \frac{\partial u}{\partial a}\right], & 0<a \leq H, \sigma_{\mathrm{v}}^{\prime}>\sigma_{\mathrm{vpc}}^{\prime}\end{cases}
$$

Under this condition, the top boundary condition is the same as equation (24), and the bottom boundary condition is as follows:

$$
\left.\frac{1}{\gamma_{\mathrm{w}}} \frac{1+e_{0}}{1+e} \frac{\partial u}{\partial a}\right|_{a=H}=i_{0} .
$$


If small-strain supposition is adopted, the governing equations for one-dimensional consolidation with consideration of the threshold gradient and stress history can be easily obtained and change as follows:

$$
\frac{\partial u}{\partial t}-\frac{d q}{d t}= \begin{cases}c_{\mathrm{v} 1} \frac{1+e_{0}}{1+e_{1}} \frac{C_{\mathrm{c}}}{C_{\mathrm{r}}} \frac{\sigma_{\mathrm{v}}^{\prime}}{\sigma_{\mathrm{v} 1}^{\prime}} \frac{\partial}{\partial a}\left[\left(\frac{\sigma_{\mathrm{v} 1}^{\prime}}{\sigma_{\mathrm{vpc}}^{\prime}}\right)^{C_{\mathrm{c}} / C_{\mathrm{k}}}\left(\frac{\sigma_{\mathrm{vpc}}^{\prime}}{\sigma_{\mathrm{v}}^{\prime}}\right)^{C_{\mathrm{r}} / C_{\mathrm{k}}}\left(1-\frac{i_{0}}{\left(1 / \gamma_{\mathrm{w}}\right)(\partial u / \partial a)}\right) \frac{\partial u}{\partial a}\right], & 0<a \leq h(t), \sigma_{\mathrm{v} 0}^{\prime} \leq \sigma_{\mathrm{v}}^{\prime} \leq \sigma_{\mathrm{vpc}}^{\prime} \\ c_{\mathrm{v} 1} \frac{1+e_{0}}{1+e_{1}} \frac{\sigma_{\mathrm{v}}^{\prime}}{\sigma_{\mathrm{v} 1}^{\prime}} \frac{\partial}{\partial a}\left[\left(\frac{\sigma_{\mathrm{v} 1}^{\prime}}{\sigma_{\mathrm{v}}^{\prime}}\right)^{C_{\mathrm{c}} / C_{\mathrm{k}}}\left(1-\frac{i_{0}}{\left(1 / \gamma_{\mathrm{w}}\right)(\partial u / \partial a)}\right) \frac{\partial u}{\partial a}\right], & 0<a \leq h(t), \sigma_{\mathrm{v}}^{\prime}>\sigma_{\mathrm{vpc}}^{\prime}\end{cases}
$$

The corresponding moving boundary condition under small-strain supposition can be expressed as follows:

$$
\left.\frac{1}{\gamma_{\mathrm{w}}} \frac{\partial u}{\partial a}\right|_{a=h(t)}=i_{0} \text {. }
$$

\section{Numerical Solutions for the Model}

To obtain the numerical solutions for the above model, the following dimensionless variables are firstly defined as follows:

$$
\begin{gathered}
x=\frac{a}{H}, \\
U=\frac{u}{\sigma_{\mathrm{v} 1}^{\prime}}, \\
Q^{0}=\frac{q_{0}}{\sigma_{\mathrm{v} 1}^{\prime}}, \\
Q=\frac{q(t)}{\sigma_{\mathrm{v} 1}^{\prime}}, \\
Q^{\mathrm{u}}=\frac{q_{\mathrm{c}}}{\sigma_{\mathrm{v} 1}^{\prime}},
\end{gathered}
$$

$$
\begin{aligned}
& R=\frac{i_{0} \gamma_{\mathrm{w}} H}{\sigma_{\mathrm{v} 1}^{\prime}}, \\
& S=\frac{\sigma_{\mathrm{v} 0}^{\prime}}{\sigma_{\mathrm{v} 1}^{\prime}}
\end{aligned}
$$

$$
\begin{gathered}
S_{\mathrm{pc}}=\frac{\sigma_{\mathrm{vpc}}^{\prime}}{\sigma_{\mathrm{v} 1}^{\prime}}, \\
T_{\mathrm{v}}=\frac{c_{\mathrm{v} 1} t}{H^{2}}, \\
T_{\mathrm{vc}}=\frac{c_{\mathrm{v} 1} t_{\mathrm{c}}}{H^{2}}, \\
X=\frac{h(t)}{H} .
\end{gathered}
$$

In terms of these dimensionless variables, the dimensionless governing equations for one-dimensional largestrain consolidation of overconsolidated clays described by equations (22) and (28) can be rearranged as follows:

$$
\begin{aligned}
& \frac{\partial U}{\partial T_{\mathrm{v}}}-\frac{d Q}{d T_{\mathrm{v}}}= \begin{cases}(S+Q-U) \frac{C_{\mathrm{c}}}{C_{\mathrm{r}}} \frac{1+e_{0}}{1+e_{1}} \frac{\partial}{\partial x}\left[\left(\frac{1}{S_{\mathrm{pc}}}\right)^{C_{\mathrm{c}} / C_{\mathrm{k}}}\left(\frac{S_{\mathrm{pc}}}{S+Q-U}\right)^{C_{\mathrm{r}} / C_{\mathrm{k}}}\left(\frac{1+e_{0}}{1+e}-\frac{R}{\partial U / \partial x}\right) \frac{\partial U}{\partial x}\right], \quad 0<x \leq X, S+Q-U \leq S_{\mathrm{pc}} \\
(S+Q-U) \frac{1+e_{0}}{1+e_{1}} \frac{\partial}{\partial x}\left[\left(\frac{1}{S+Q-U}\right)^{C_{\mathrm{c}} / C_{\mathrm{k}}}\left(\frac{1+e_{0}}{1+e}-\frac{R}{\partial U / \partial x}\right) \frac{\partial U}{\partial x}\right], & 0<x \leq X, S+Q-U>S, \quad,\end{cases} \\
& \frac{\partial U}{\partial T_{\mathrm{v}}}-\frac{d Q}{d T_{\mathrm{v}}}= \begin{cases}(S+Q-U) \frac{1+e_{0}}{1+e_{1}} \frac{\partial}{\partial x}\left[\left(\frac{1}{S_{\mathrm{pc}}}\right)^{C_{\mathrm{c}} / C_{\mathrm{k}}}\left(\frac{S_{\mathrm{pc}}}{S+Q-U}\right)^{C_{\mathrm{r}} / C_{\mathrm{k}}}\left(\frac{1+e_{0}}{1+e}-\frac{R}{\partial U / \partial x}\right) \frac{\partial U}{\partial x}\right], & 0<x \leq 1, S \leq S+Q-U \leq S_{\mathrm{pc}}, \\
(S+Q-U) \frac{1+e_{0}}{1+e_{1}} \frac{\partial}{\partial x}\left[\left(\frac{1}{S+Q-U}\right)^{C_{\mathrm{c}} / C_{\mathrm{k}}}\left(\frac{1+e_{0}}{1+e}-\frac{R}{\partial U / \partial x}\right) \frac{\partial U}{\partial x}\right], & 0<x \leq 1, S+Q-U>S S_{\mathrm{pc} .}\end{cases}
\end{aligned}
$$


In terms of dimensionless variables, the solution condition described by equations (24)-(27) can be rewritten as follows:

$$
\begin{aligned}
U\left(0, T_{\mathrm{v}}\right) & =0, \\
U\left[X\left(T_{\mathrm{v}}\right), T_{\mathrm{v}}\right] & =Q, \\
\left.\frac{1+e_{0}}{1+e} \frac{\partial U}{\partial x}\right|_{x=X\left(T_{\mathrm{v}}\right)} & =R, \\
U(x, 0) & =Q^{0} .
\end{aligned}
$$

Under small strain assumption, the corresponding solution condition can be expressed as follows:

$$
\begin{aligned}
U\left(0, T_{\mathrm{v}}\right) & =0, \\
U\left[X\left(T_{\mathrm{v}}\right), T_{\mathrm{v}}\right] & =Q, \\
\left.\frac{\partial U}{\partial x}\right|_{x=X\left(T_{\mathrm{v}}\right)} & =R, \\
U(x, 0) & =Q^{0} .
\end{aligned}
$$

In order to obtain finite differential solutions for above models, a differential grid is placed in the $x-T_{\mathrm{v}}$ plane with spatial isometry and nonisometry time steps. As shown in Figure 5, the spatial domain is divided into $n$ equal thin layers, and the dimensionless value of the thickness of each thin layer is $\Delta x$. The $j$ th nodal point of the spatial domain is noted as $x_{j}$, and $x_{j}=j \Delta x, j=0,1,2,3, \ldots, n$. So the nodal point of the top surface is $x_{0}=0$, and the nodal point of the bottom surface is $x_{n}=1$. Meantime, the time domain $T_{\mathrm{v}}$ is also divided into a number of small time intervals. If the $k$ th time interval is noted as $\Delta T_{\mathrm{v} k}(k=1,2,3,4, \ldots)$, the final time of the $k$ th time interval, $T_{\mathrm{v} k}$, is as follows:

$$
T_{\mathrm{vk}}=\sum_{r=1}^{k} \Delta T_{\mathrm{v} r}
$$

The dimensional value of current effective stress at the $j$ th nodal point, $S_{j}$, can be obtained by the following equation:

$$
S_{j}=\frac{\sigma_{\mathrm{v} 0}^{\prime}(j \Delta x H)}{\sigma_{\mathrm{v} 1}^{\prime}}
$$

in which $\sigma_{v 0}^{\prime}(j \Delta x H)$ can be determined by equation (8). The dimensional value of preconsolidation stress at the $j$ th nodal point, $S_{\mathrm{pcj} j}$, can be calculated by the following equation:

$$
S_{\mathrm{pc} j}=\frac{\sigma_{\mathrm{vpc}}^{\prime}(j \Delta x H)}{\sigma_{\mathrm{v} 1}^{\prime}}
$$

in which $\sigma_{\mathrm{vpc}}^{\prime}(j \Delta x H)$ can be obtained by equations (1) and (8). The dimensionless value of excess pore water pressure when $x_{j}=j \Delta x$ and $T_{\mathrm{v}}=T_{\mathrm{v} k}$ is noted as $U_{j}^{k}$, and $Q^{k}$ is the dimensionless value of time-dependent load $q(t)$ when $T_{\mathrm{v}}=T_{\mathrm{v} k}$. The void ratio at the $j$ th nodal point, $e_{0 j}$ and $e_{\mathrm{pc} j}$, can be determined by $S_{j}$ and $S_{\mathrm{pcj}}$ according to equations (3) and (4). In order to solve the moving boundary problem, the following two assumptions are made:

(1) The water flow in the first thin layer occurs as long as the external load is applied to the surface of clays. The flow front reached the bottom of the second thin layer after the first interval.

(2) If the water flow occurs at some point of a thin clay layer, the water flow occurs during the whole thin layer at the same time, and the whole thin layer begins to consolidate at the same time. If the flow front reaches the bottom of the $j$ th thin layer at $T_{\mathrm{v}}=$ $T_{v k-1}$ and the average hydraulic gradient in the $(j+$ 1)th thin layer is greater than the threshold gradient, therefore, the flow front is supposed to reach the bottom of the $(j+1)$ th thin layer during the next time interval $\Delta T_{\mathrm{v} k}$.

If the clay layer is divided into many thin layers, the computational error caused by assumption (1) can be ignored. Moreover, assumption (1) has been already adopted by Pascal et al. [16] in the study of consolidation with consideration of a threshold gradient. Similar to the studies $[28,29]$, the differential equation corresponding to equation (33) during the first time interval $\Delta T_{\mathrm{vl}}$ can be expressed as follows:

$$
\begin{aligned}
U_{1}^{1}= & U_{1}^{0}+\left(Q^{1}-Q^{0}\right) \\
& +\lambda^{1} \beta_{1}^{1}\left[\alpha_{1+1 / 2}^{1}\left(U_{2}^{1}-U_{1}^{1}\right)-\alpha_{1-1 / 2}^{1}\left(U_{1}^{1}-U_{0}^{1}\right)\right]
\end{aligned}
$$

where $\lambda^{1}=\Delta T_{\mathrm{v} 1} /(\Delta x)^{2}, \beta_{1}^{1}, \alpha_{1-1 / 2}^{1}$, and $\alpha_{1+1 / 2}^{1}$ are given in Appendix. When the moving boundary reaches the second thin layer, the top boundary and moving boundary conditions can be expressed in terms of the discrete point as follows:

$$
\begin{aligned}
U_{0}^{1} & =0 \\
\left(3 U_{2}^{1}-4 U_{1}^{1}+U_{0}^{1}\right) & =\frac{2 R \Delta x\left(1+e_{2}^{1}\right)}{1+e_{02}}, \\
U_{2}^{1} & =Q^{1} .
\end{aligned}
$$

With equations (42) and (43), the following equation can be obtained:

$$
U_{1}^{1}=\frac{3 Q^{1}-2 R \Delta x\left(1+e_{2}^{1}\right) /\left(1+e_{02}\right)}{4} .
$$

Substituting equation (44) into equation (40), the time for the moving flow front to reach the second thin layer $\left(T_{2}\right)$ can be derived:

$$
T_{2}=T_{\mathrm{v} 1}=\Delta T_{\mathrm{v} 1}=\frac{U_{1}^{1}-Q^{1}}{\beta_{1}^{1}\left[\alpha_{1+1 / 2}^{1}\left(Q^{1}-U_{1}^{1}\right)-\alpha_{1-1 / 2}^{1}\left(U_{1}^{1}-U_{0}^{1}\right)\right]} .
$$

$Q^{1}$ also is the function of $T_{2}$, so $T_{2}$ can be obtained by the iteration method. When $T_{\mathrm{v}}>T_{2}$, the moving flow front still stays in the second thin layer or moves down to another thin layer. If the moving flow front stays in the $j$ th $(2 \leq j<n)$ thin 


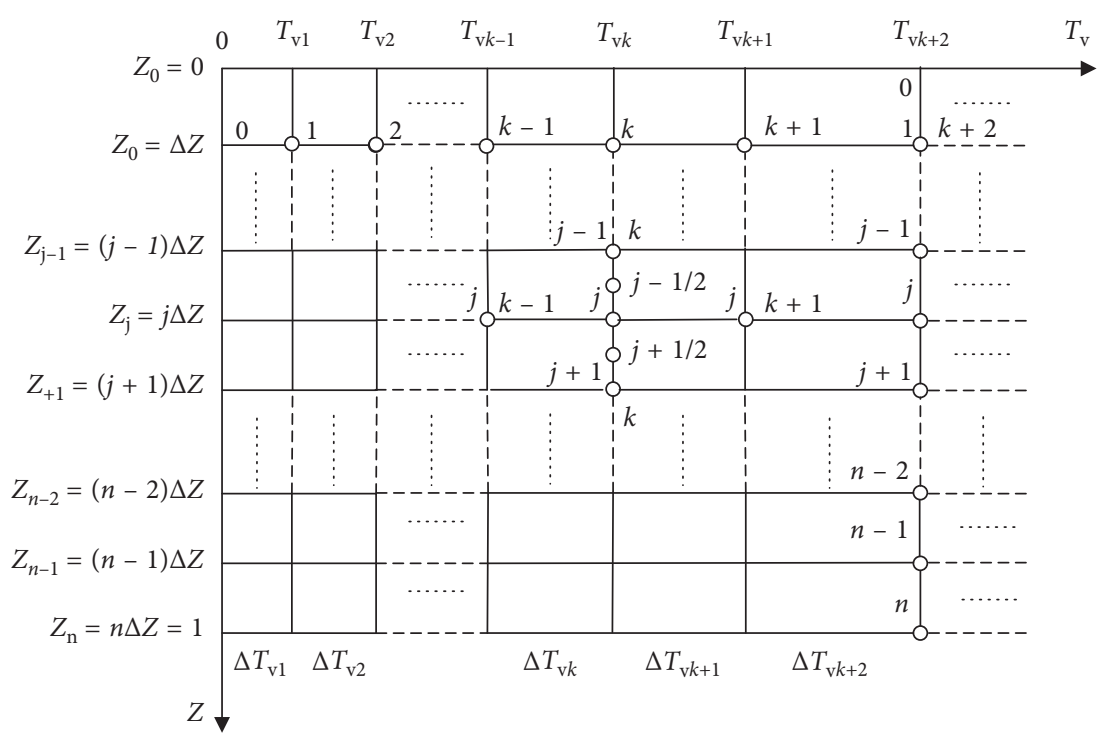

Figure 5: A differential grid in the $x-T_{\mathrm{v}}$ plane.

layer at time $T_{\mathrm{v} k-1}$, the differential equation and the moving boundary condition during the $k$ th interval $\Delta T_{\mathrm{v} k}$ are as follows:

$$
\begin{aligned}
U_{l}^{k}= & U_{l}^{k-1}+\left(Q^{k}-Q^{k-1}\right)+\lambda^{k} \beta_{l}^{k-1}\left[\alpha_{l+1 / 2}^{k-1}\left(U_{l+1}^{k}-U_{l}^{k}\right)\right. \\
& \left.-\alpha_{l-1 / 2}^{k-1}\left(U_{l}^{k}-U_{l-1}^{k}\right)\right], \quad k \geq 2,0<l \leq j-1, \\
U_{l}^{k}= & Q^{k}, \quad k \geq 2, l \geq j, \\
& \left(3 U_{j}^{k}-4 U_{j-1}^{k}+U_{j-2}^{k}\right)=\frac{2 R \Delta x\left(1+e_{j}^{k-1}\right)}{1+e_{0 j}},
\end{aligned}
$$

where $\lambda^{k}=\Delta T_{\mathrm{v} k} /(\Delta x)^{2}, \beta_{l}^{k}, \alpha_{l-1 / 2}^{k}$, and $\alpha_{l+1 / 2}^{k}$ are given in Appendix.

If the following equation can be satisfied at time $T_{\mathrm{vk}}$, according to supposition (2), the flow front reaches the bottom of the $(j+1)$ th thin layer during the next time interval $\Delta T_{\mathrm{v} k+1}$ :

$$
\frac{1+e_{0 j}}{1+e_{j}^{k}} \frac{U_{j+1}^{k}-U_{j}^{k}}{\Delta x} \geq R .
$$

On the contrary, if equation (49) cannot be satisfied, the moving flow front still stays in the bottom of the $j$ th thin layer during the next time interval $\Delta T_{\mathrm{v} k+1}$. Denote the time for the moving flow front to reach $x_{j+1}$ as $T_{j+1}$. If equation (49) is satisfied at time $T_{\mathrm{v} k}, T_{j+1}$ can be determined by the following equation:

$$
T_{j+1}=T_{\mathrm{v} k}=\sum_{r=1}^{k} \Delta T_{\mathrm{v} r}, \quad j=2,3,4, \ldots, n-1 .
$$

When the moving flow front reaches the bottom of the clay layer, the moving boundary turns into a fixed boundary. Under this case, the boundary condition can be expressed in terms of the nodal point as follows:

$$
\left(3 U_{n}^{k}-4 U_{n-1}^{k}+U_{n-2}^{k}\right)=\frac{2 R \Delta x\left(1+e_{n}^{k-1}\right)}{1+e_{0 n}} .
$$

Excess pore water pressure may not thoroughly dissipate for the existence of the hydraulic gradient. The excess pore water pressure at time $T_{\mathrm{vk+1}}$ can be considered as the residual value of excess pore water pressure if the norm of the differences between $U_{j}^{k+1}$ and $U_{j}^{k}$ is small enough, that is,

$$
\max \left(\frac{U_{j}^{k+1}-U_{j}^{k}}{U_{j}^{k+1}}\right) \leq \varepsilon, \quad j=1,2,3, \ldots, n,
$$

where $\varepsilon$ is a small number to be specified according to the tolerable error. By a number of calculations, small distinctions come out between $\varepsilon=10^{-4}$ and $\varepsilon=10^{-5}$. Therefore, $\varepsilon=10^{-4}$ is adopted in the following analysis to complete the process of calculation rapidly. If equation (52) is valid, the residual excess pore water pressure, $U_{j}^{\infty}$, can be determined by $U_{j}^{k+1}$. The final void ratio also can be determined by equation (5) or equation (6). According to the study on large-strain consolidation in the Lagrangian coordinate [26], the settlement of the clay layer at time $t, S_{t}$, can be derived:

$$
d S_{t}=\frac{e_{0}-e}{1+e_{0}} d a .
$$

The settlement of the clay layer $S_{t}$ can be obtained by integrating equation (53) with respect to $a$ from 0 to $H$ :

$$
S_{t}=\int_{0}^{H} \frac{e_{0}-e}{1+e_{0}} d a=\sum_{j=1}^{n} \frac{e_{0 j}-e_{j}^{k}}{1+e_{0 j}} .
$$

The final settlement of the clay layer, $S_{\infty}$, can be expressed as follows:

$$
S_{\infty}=\int_{0}^{H} \frac{e_{0}-e_{j}^{\infty}}{1+e_{0}} d a=\frac{H}{n} \sum_{j=1}^{n} \frac{e_{0 j}-e_{j}^{\infty}}{1+e_{0 j}} .
$$

The average degree of consolidation in terms of deformation at $T_{\mathrm{v} k}, U_{\mathrm{st}}$, is as follows: 
TABLE 1: The parameters.

\begin{tabular}{lccccccccccccccc}
\hline Parameters & $H(\mathrm{~m})$ & $\sigma_{\mathrm{v} 1}^{\prime}(\mathrm{kPa})$ & $e_{1}$ & $k_{\mathrm{v} 1}\left(10^{-8} \mathrm{~m} / \mathrm{s}\right)$ & $\sigma_{\mathrm{pc}}(\mathrm{kPa})$ & $G_{\mathrm{s}}$ & $\gamma_{\mathrm{w}}\left(\mathrm{kN} / \mathrm{m}^{3}\right)$ & $q_{\mathrm{c}}(\mathrm{kPa})$ & $T_{\mathrm{vc}}$ & $C_{\mathrm{c}}$ & $C_{\mathrm{k}}$ & $C_{\mathrm{r}}$ & $i_{0}$ & $\varepsilon$ \\
\hline Values & 20 & 50 & 1.5 & 1.0 & 25 & 2.75 & 10 & 200 & 0.05 & 0.85 & 0.8 & 0.05 & 0.5 & $10^{-4}$ \\
\hline
\end{tabular}

$$
U_{\text {st }}=\frac{S_{t}}{S_{\infty}}
$$

The average degree of consolidation in terms of excess pore water pressure at $T_{\mathrm{v} k}, U_{\mathrm{pt}}$, can be written as follows:

$$
U_{\mathrm{pt}}=\int_{0}^{H} \frac{q(t)-u}{q_{\mathrm{c}}} d a= \begin{cases}\frac{Q^{k}}{Q^{u}}-\frac{1}{n Q^{u}} \sum_{j=1}^{n} \frac{U_{j-1}^{k}+U_{j}^{k}}{2}, & T_{\mathrm{v}} \leq T_{\mathrm{vc}}, \\ 1-\frac{1}{n Q^{u}} \sum_{j=1}^{n} \frac{U_{j-1}^{k}+U_{j}^{k}}{2}, & T_{\mathrm{v}}>T_{\mathrm{vc}} .\end{cases}
$$

\section{Analysis of Consolidation Behavior}

To study the influence of one parameter on consolidation behavior, other parameters may remain constant, and the parameters in Table 1 are adopted in the following analysis.

6.1. Influences on the Location of the Moving Flow Front. The threshold hydraulic gradient gives rise to the existence of the flow front and moving flow boundary. As shown in Figure 6 , the greater the $i_{0}$, the longer the time needed by the flow front reaching the bottom of the clay layer. Moreover, according to the previous studies [16, 17], the flow front cannot reach the bottom of the clay layer when $i_{0}$ is great enough. If stress history and large-strain supposition were considered, this consolidation behavior about the location of the flow front would not change. In Figure 6 , when $i_{0}=1.5$, the moving flow front cannot reach the bottom of the clay layer because the threshold hydraulic gradient is large enough compared with the external load and the thickness of the clay layer.

Figure 7 describes the influence of different geometric suppositions on the moving rate of the flow front. In general, the flow front under large-strain supposition moves faster than that under small-strain supposition. However, the difference in moving rate between large strain and small strain is not evident when the threshold hydraulic gradient is equal to 0.1 (in Figure $7(\mathrm{a})$ ). It must be noted that the preconsolidation pressure also has influence on the moving rate of the flow front. The moving rate of the flow front increases with the increasing value of preconsolidation pressure. Furthermore, the difference in moving rate of the flow front between large strain and small strain decreases with the increasing value of preconsolidation pressure (in Figure 7(b)).

6.2. Influences on the Dissipation of Excess Pore Water Pressure. Figure 8(a) indicates that the residual excess pore water pressure in clays with large-strain supposition is

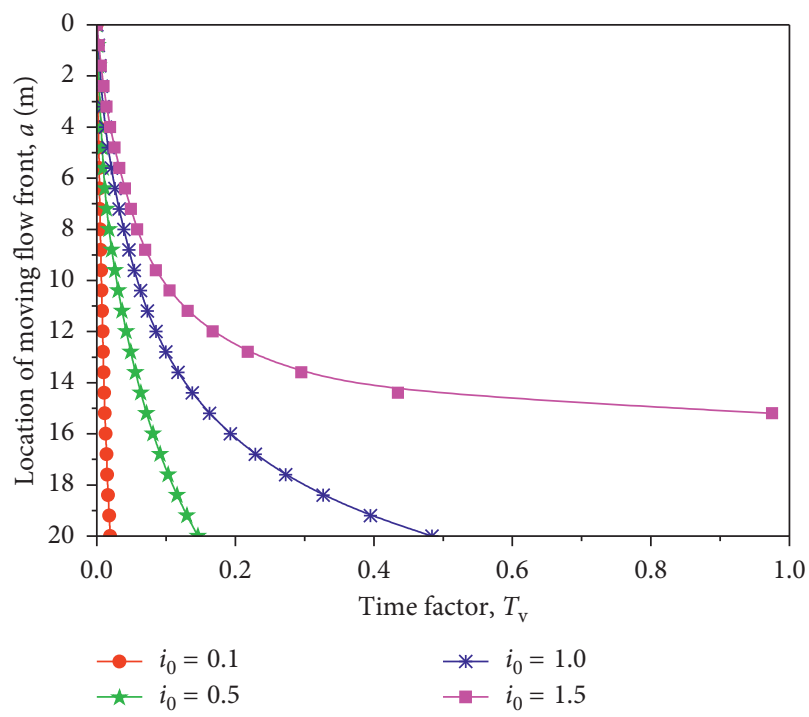

Figure 6: Influence of $i_{0}$ on the moving flow boundary.

smaller than that with small-strain supposition when $T_{\mathrm{v}}=$ 0.5 . At the same time, the residual excess pore water pressure with $i_{0}=0.1$ is smaller than that with $i_{0}=0.5$. It further indicates that the dissipation rate of excess pore water pressure decreases with increasing $i_{0}$. Figure $8(\mathrm{~b})$ describes the dissipation of excess pore water pressure with time and indicates that the dissipation rate of excess pore water pressure with large-strain supposition is faster than that with small-strain supposition during the whole consolidation process. The difference in the dissipation rate of excess pore water pressure between large strain and small strain becomes evident with an increase in the threshold hydraulic gradient. Moreover, the final residual excess pore water pressure with large-strain supposition is smaller than that with smallstrain supposition.

The preconsolidation pressure also has great influence on the dissipation of excess pore water pressure (in Figure 9). The dissipation rate of excess pore water increases with the increasing preconsolidation pressure when the threshold hydraulic gradient is constant. However, the preconsolidation pressure has no influence on the value of the final residual excess pore water pressure. If the preconsolidation pressure is also the same, the dissipation rate of excess pore water pressure with large-strain supposition is faster than that with small-strain supposition.

6.3. Influences on the Average Degree of Consolidation. Since the dissipation rate of excess pore water pressure decreases with an increase in the value of the threshold hydraulic gradient, the average degree in terms of excess pore water pressure should increase with the decreasing threshold hydraulic gradient at the same time (Figure 10). 


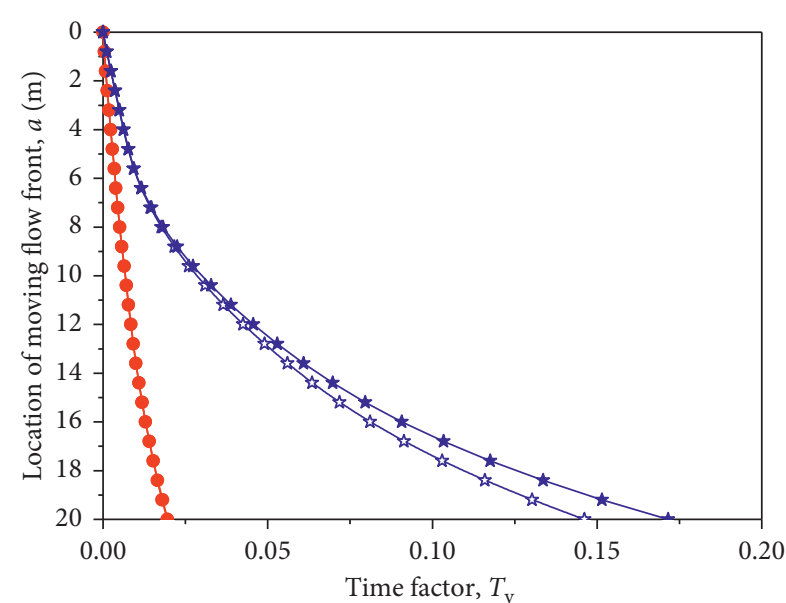

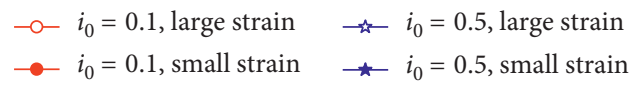

(a)

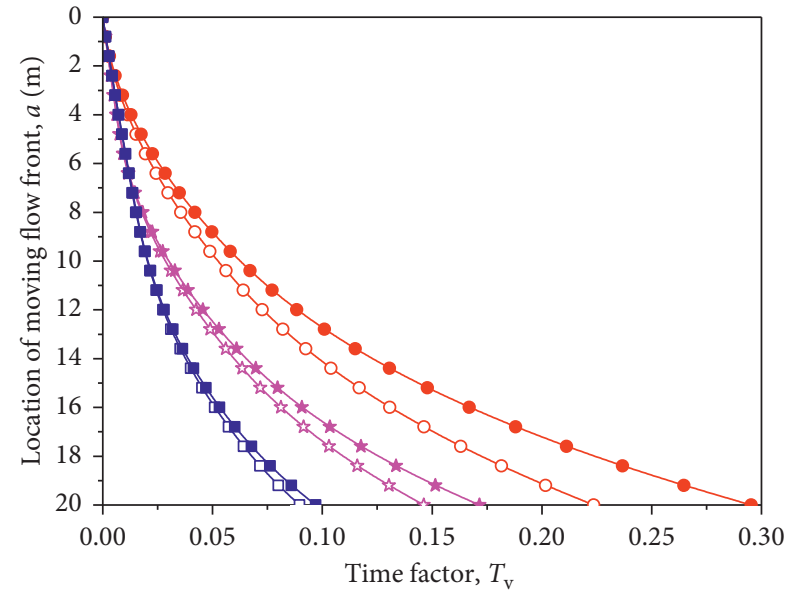

$\multimap-\sigma_{\mathrm{pc}}=0 \mathrm{kPa}$, large strain $\rightarrow$ $\sigma_{\mathrm{pc}}=25 \mathrm{kPa}$, small strain

$\multimap \sigma_{\mathrm{pc}}=0 \mathrm{kPa}$, small strain $\longrightarrow-\sigma_{\mathrm{pc}}=50 \mathrm{kPa}$, large strain

$\leadsto \sigma_{\mathrm{pc}}=25 \mathrm{kPa}$, large strain $\rightarrow \sigma_{\mathrm{pc}}=50 \mathrm{kPa}$, small strain

(b)

FIGURE 7: Influences of geometric suppositions on the moving rate of the flow front: (a) under different threshold hydraulic gradient $i_{0}$; (b) under different preconsolidation pressure $\sigma_{\mathrm{pc}}$.

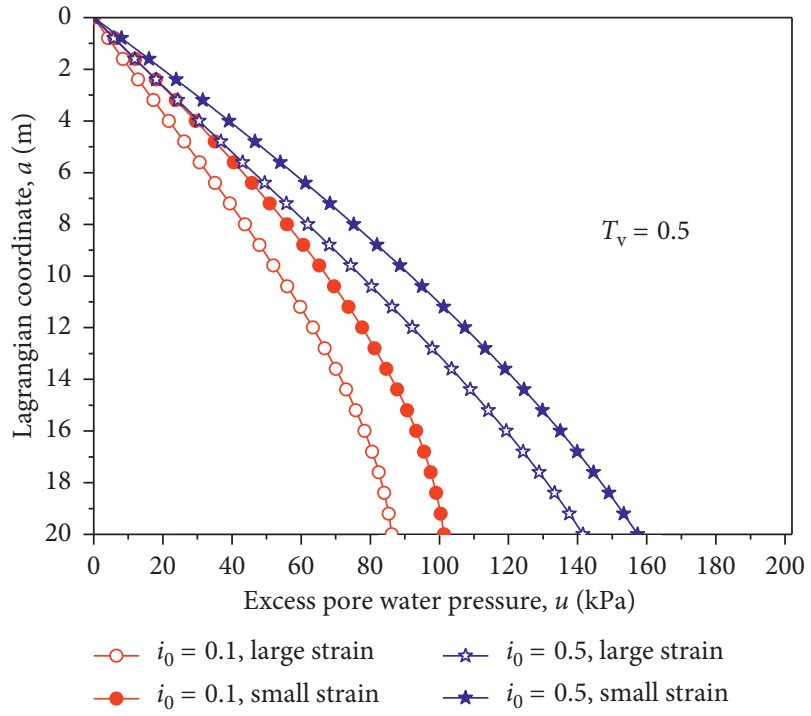

(a)

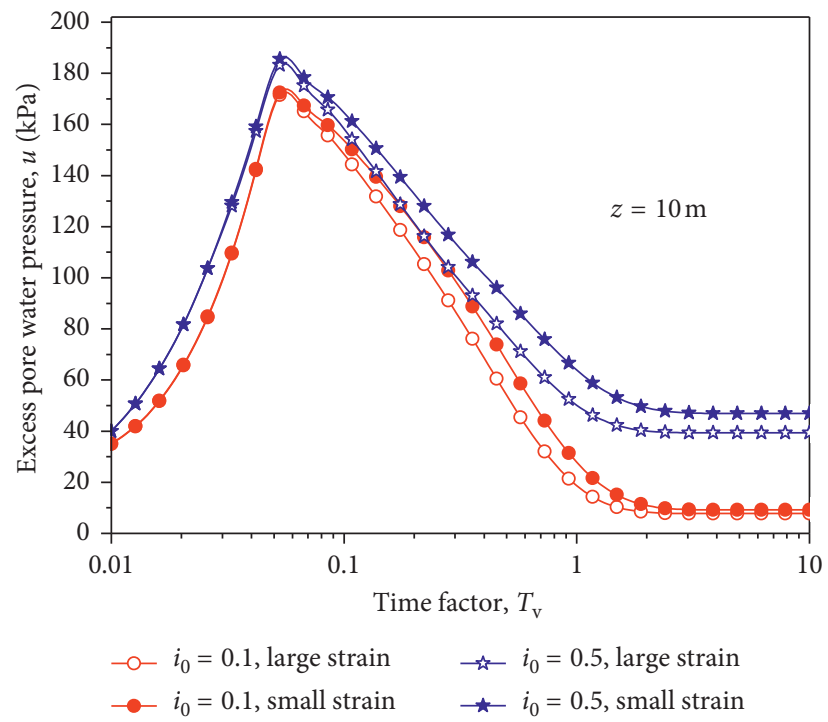

(b)

Figure 8: Influences of geometric suppositions on the dissipation of excess pore water pressure. (a) Curves of excess pore water pressure versus Lagrangian coordinate $a$ when $T_{\mathrm{v}}=0.5$. (b) Curves of excess pore water pressure versus time factor $T_{\mathrm{v}}$ at $z=10 \mathrm{~m}$.

The consolidation rate with large-strain supposition is faster than that with small-strain supposition, and the final average degree in terms of excess pore water pressure with largestrain supposition is also greater than that with small-strain supposition. For the existence of the threshold hydraulic gradient, the excess pore water pressure cannot thoroughly dissipate, and the final average degree in terms of excess pore water pressure cannot run to 1 . The difference in the average degree between large strain and small strain may become evident with an increase in $i_{0}$. If $i_{0}$ is so small (for instance, $i_{0}$ $=0.1$, then this difference can be neglected.
Figure 11 indicates that the preconsolidation pressure of overconsolidated clays has influences on the consolidation rate. If the threshold hydraulic gradient is constant, the consolidation rate increases with the increasing preconsolidation pressure. If both the preconsolidation pressure and the threshold hydraulic are constant, the consolidation rate with large-strain supposition is faster than that with small-strain supposition. It should be noted that the preconsolidation pressure has no influence on the final average degree when the dissipation of excess pore water pressure is completed. 


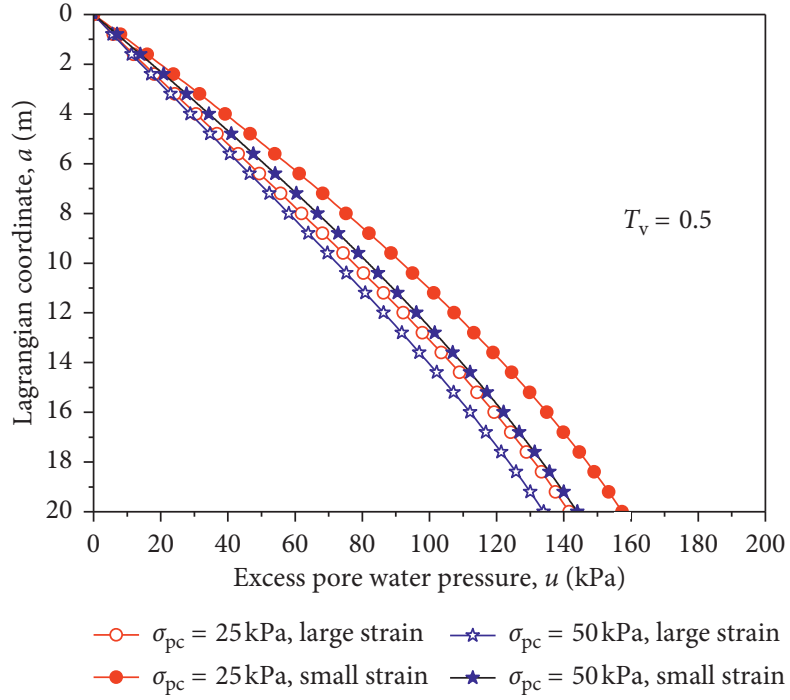

(a)

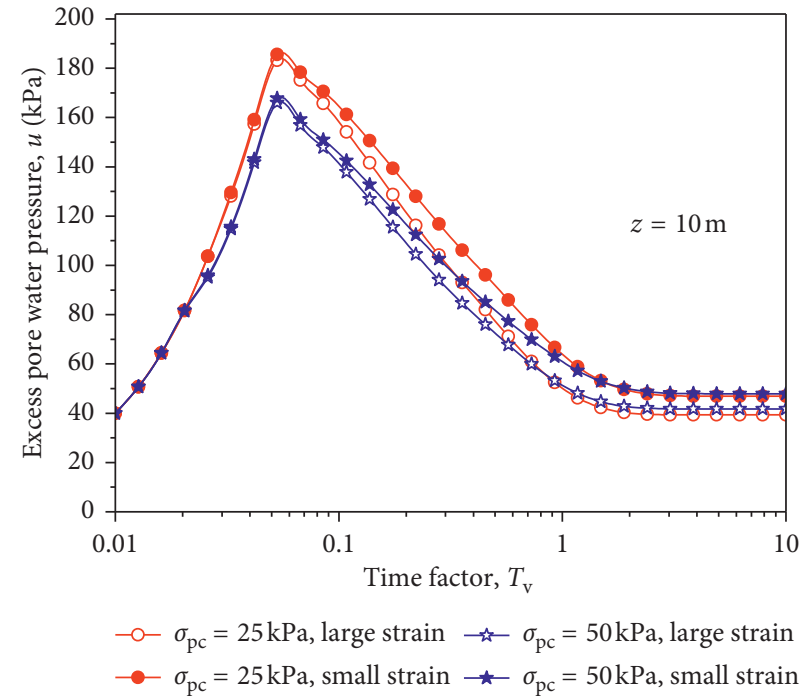

(b)

FIGURE 9: Influences of preconsolidation pressure on the dissipation of excess pore water pressure. (a) Curves of excess pore water pressure versus the Lagrangian coordinate $a$ when $T_{\mathrm{v}}=0.5$. (b) Curves of excess pore water pressure versus time factor $T_{\mathrm{v}}$ at $z=10 \mathrm{~m}$.

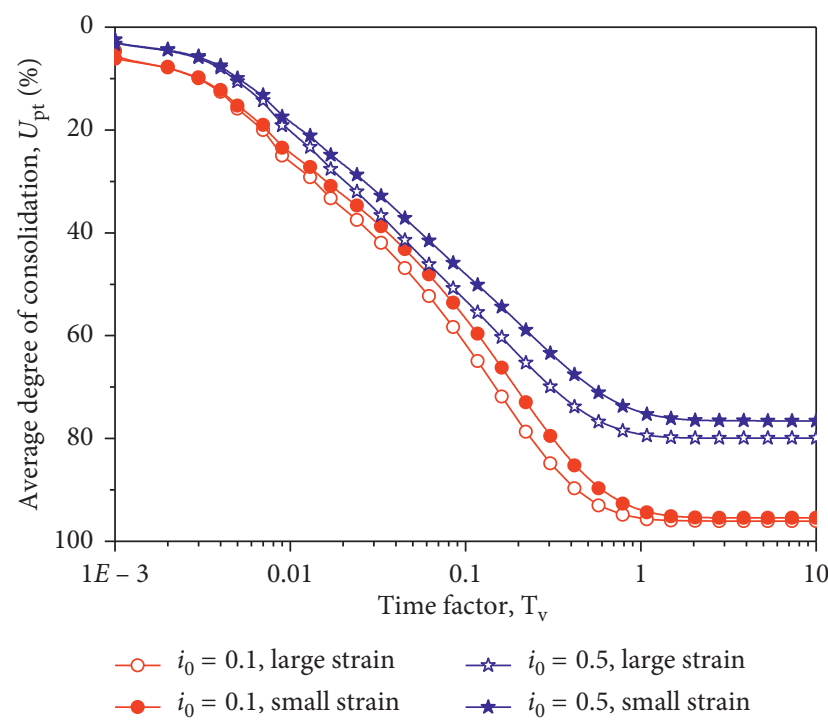

FIGURE 10: Influence of geometric suppositions on $U_{\mathrm{pt}}$ under different $i_{0}$.

6.4. Influences on the Settlement of the Clay Layer. The threshold hydraulic gradient has great influence on the settlement of the clay layer. As shown in Figure 12, the final settlement decreases with the increasing threshold hydraulic gradient. From Figure 13, it can be seen that the settlement of the clay layer decreases with the increasing preconsolidation pressure of overconsolidated clays. If the threshold gradient and the preconsolidation pressure remain constant, the settlement of the clay layer with largestrain supposition is greater than that with small-strain supposition. However, this difference in settlement between large strain and small strain increases with an increase in threshold hydraulic gradient and a decrease in

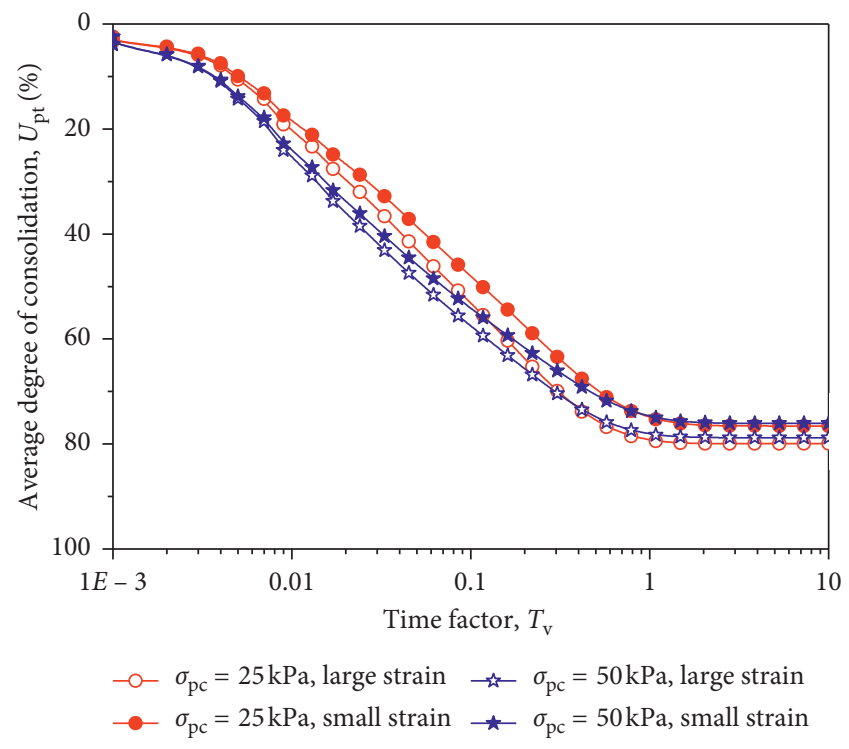

FIGURE 11: Influence of geometric supposition on $U_{\mathrm{pt}}$ under different preconsolidation pressure.

preconsolidation pressure of overconsolidated clays. Especially, if $i_{0}=0.0001$ which can be approximately considered as Darcy's law, the settlement of the clay layer under different geometric suppositions is the same. The reason for this phenomenon is that the residual excess pore water pressure under large-strain supposition with consideration of the threshold hydraulic gradient is smaller than that under small-strain supposition (in Figure 8). Therefore, when the threshold hydraulic gradient in clays under a low hydraulic gradient is considered, the final settlement under largestrain assumption is greater than that under small-strain assumption. 


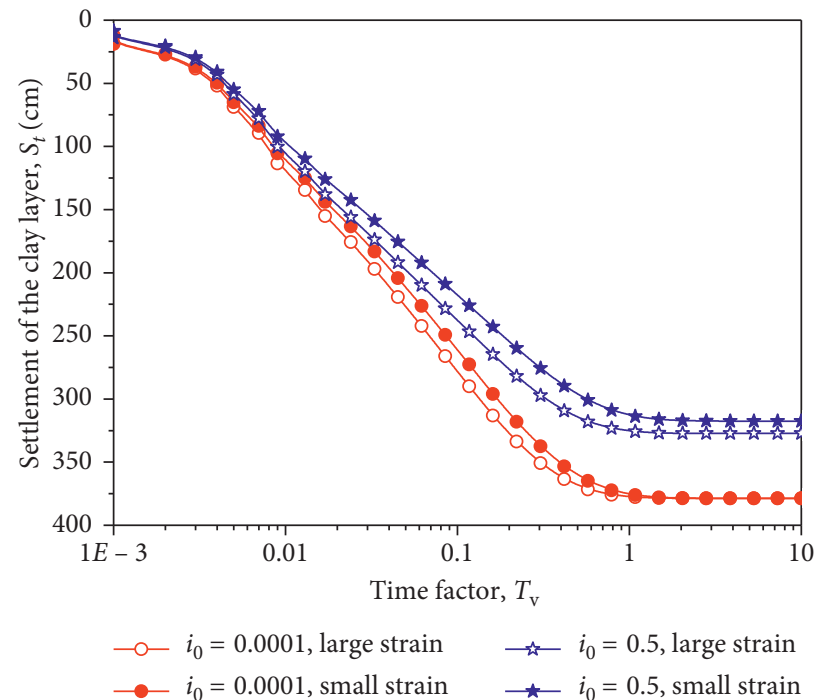

FIgURE 12: Influence of geometric supposition on $S_{t}$ under different $i_{0}$.

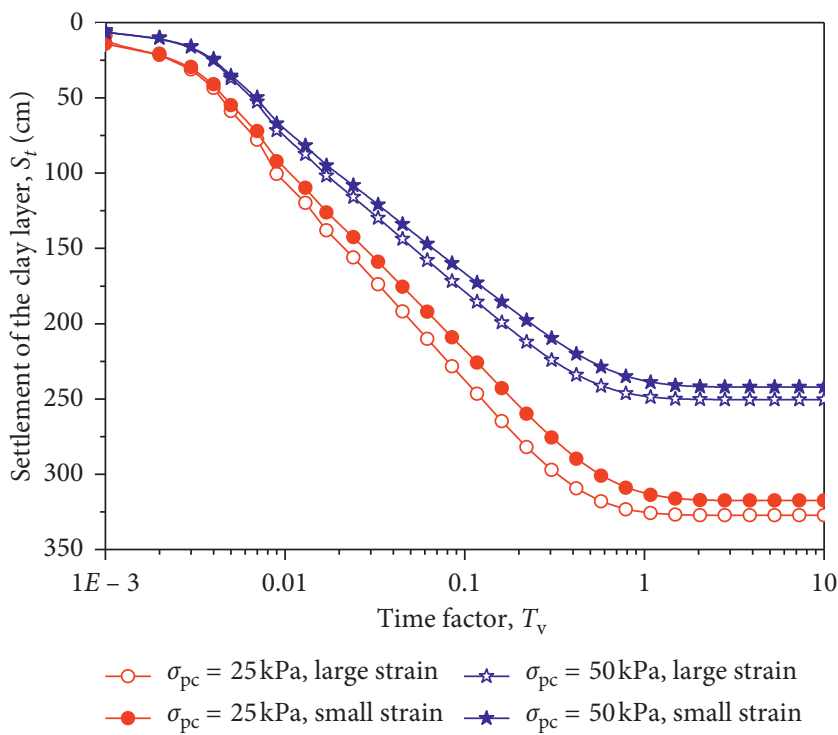

Figure 13: Influence of geometric supposition on $S_{t}$ under different preconsolidation pressure.

\section{Conclusions}

In case of one-dimensional large-strain consolidation of overconsolidated clays, the moving rate of the flow front resulted by the threshold hydraulic gradient and the dissipation rate of excess pore water pressure decrease with the increasing threshold gradient. The greater the threshold hydraulic gradient is, the greater the final residual excess pore water pressure is and the smaller the final settlement of the clay layer is. The consolidation rate of overconsolidated clays with the threshold hydraulic gradient is faster than that of normally consolidated clays with the same threshold gradient, and it increases with an increase in preconsolidation pressure. The dissipation rate of excess pore water pressure with large-strain supposition is faster than that with small-strain supposition, and this difference between them increases with an increase in threshold gradient and a decrease in preconsolidation pressure. If Darcy's law is valid, the final settlement with large-strain supposition is the same as that with small-strain supposition. However, if a threshold hydraulic gradient exists in overconsolidated clays, the final settlement with large-strain supposition is greater than that with small-strain supposition.

\section{Appendix}

The Expressions of $\beta_{j}^{k-1}, \alpha_{j-1 / 2}^{k-1}$, and $\alpha_{j+1 / 2}^{k-1}$

The expressions of $\beta_{j}^{k-1}, \alpha_{j-1 / 2}^{k-1}$, and $\alpha_{j+1 / 2}^{k-1}$ in numerical solutions for the excess pore water pressure in equation (46) are as follows: 


$$
\begin{aligned}
& \beta_{j}^{k-1}= \begin{cases}\frac{\left(S_{j}+Q^{k-1}-U_{j}^{k-1}\right)\left(C_{c} / C_{\mathrm{r}}\right)\left(1+e_{0 j}\right)}{1+e_{1}}, & S_{j}+Q^{k-1}-U_{j}^{k-1} \leq S_{\mathrm{pcj}}, \\
\frac{\left(S_{j}+Q^{k-1}-U_{j}^{k-1}\right)\left(1+e_{0 j}\right)}{1+e_{1}}, & S_{j}+Q^{k-1}-U_{j}^{k-1}>S_{\mathrm{pcj}},\end{cases} \\
& \alpha_{j+1 / 2}^{k-1}= \begin{cases}\left(\frac{1}{\left(S_{\mathrm{pcj}+1}+S_{\mathrm{pcj}}\right) / 2}\right)^{C_{c} / C_{k}}\left(\frac{\left(S_{\mathrm{pcj+1}}+S_{\mathrm{pc} j}\right) / 2}{\left(\left(S_{j+1}+S_{j}\right) / 2\right)+Q^{k}-\left(\left(U_{j+1}^{k-1}+U_{j}^{k-1}\right) / 2\right)}\right)^{C_{\mathrm{r}} C_{k}}\left(\frac{1+\left(\left(e_{0 j+1}+e_{0 j}\right) / 2\right)}{1+\left(\left(e_{j+1}^{k-1}+e_{j}^{k-1}\right) / 2\right)}-\frac{R}{\left(U_{j+1}^{k-1}-U_{j}^{k-1}\right) / \Delta x}\right), & S_{j}+Q^{k-1}-U_{j}^{k-1} \leq S_{\mathrm{pcj}}, \\
\left(\frac{1}{\left(\left(S_{j+1}+S_{j}\right) / 2\right)+Q^{k}-\left(\left(U_{j+1}^{k-1}+U_{j}^{k-1}\right) / 2\right)}\right)^{C_{c} / C_{\mathrm{k}}}\left(\frac{1+\left(\left(e_{0 j+1}+e_{0 j}\right) / 2\right)}{1+\left(\left(e_{j+1}^{k-1}+e_{j}^{k-1}\right) / 2\right)}-\frac{R}{\left(U_{j+1}^{k-1}-U_{j}^{k-1}\right) / \Delta x}\right), & S_{j}+Q^{k-1}-U_{j}^{k-1}>S_{\mathrm{pcj}},\end{cases} \\
& \alpha_{j-1 / 2}^{k-1}= \begin{cases}\left(\frac{1}{\left(S_{\mathrm{pcj}}+S_{\mathrm{pcj}-1}\right) / 2}\right)^{C_{\mathrm{c}} / C_{\mathrm{k}}}\left(\frac{\left(S_{\mathrm{pcj}}+S_{\mathrm{pcj-1}}\right) / 2}{\left(\left(S_{j}+S_{j-1}\right) / 2\right)+Q^{k}-\left(\left(U_{j}^{k-1}+U_{j-1}^{k-1}\right) / 2\right)}\right)^{C_{\mathrm{r}} / C_{\mathrm{k}}}\left(\frac{1+\left(\left(e_{0 j}+e_{0 j-1}\right) / 2\right)}{1+\left(\left(e_{j}^{k-1}+e_{j-1}^{k-1}\right) / 2\right)}-\frac{R}{\left(U_{j}^{k-1}-U_{j-1}^{k-1}\right) / \Delta x}\right), & S_{j}+Q^{k-1}-U_{j}^{k-1} \leq S_{\mathrm{pcj}}, \\
\left(\frac{1}{\left(\left(S_{j}+S_{j-1}\right) / 2\right)+Q^{k}-\left(\left(U_{j}^{k-1}+U_{j-1}^{k-1}\right) / 2\right)}\right)^{C_{c} / C_{k}}\left(\frac{1+\left(\left(e_{0 j}+e_{0 j-1}\right) / 2\right)}{1+\left(\left(e_{j}^{k-1}+e_{j}^{k-1}\right) / 2\right)}-\frac{R}{\left(U_{j}^{k-1}-U_{j-1}^{k-1}\right) / \Delta x}\right), & S_{j}+Q^{k-1}-U_{j}^{k-1}>S_{\mathrm{pcj}} .\end{cases}
\end{aligned}
$$

\section{Notations}

$\alpha_{j+1 / 2}^{k-1}$ and $\alpha_{j-1 / 2}^{k-1}$ : Coefficients in finite differential solutions

$\beta_{j}^{k-1}:$

$\varepsilon:$

$\lambda^{k}$ :

$\sigma_{\mathrm{pc}}:$

$\sigma_{\mathrm{v} 0}^{\prime}:$

$\sigma_{\mathrm{vpc}}^{\prime}:$

$\gamma_{\mathrm{w}}$ :

$a:$

$C_{c}:$

$C_{\mathrm{k}}$ :

$C_{\mathrm{r}}$ :

$\mathrm{C}_{\mathrm{v}}$ :

e:

$e_{0}:$

$e_{0 j}$ :

$e_{1}$ :

$e_{j}^{k}:$
$e_{j}^{\infty}:$

$e_{\mathrm{pc}}:$

$e_{\mathrm{pcj}}:$

$G_{\mathrm{s}}:$

$H$ :

$h(t)$ : which are determined by equations (A.2) and (A.3)

$i$ :

$i_{0}:$

$m_{\mathrm{v}}$ :

$n:$

Q: Coefficient in finite differential solution which is determined by equation (A.1) A small number to be specified Coefficient in finite differential solutions which is determined by $\Delta T_{v k} / \Delta x^{2}$ The reduction in effective stress for an overconsolidated clay layer Current effective stress resulting from self-weight stress

Preconsolidation stress

Unit weight of water

Lagrangian coordinate

Compression index

Permeability index

Recompression index

Coefficient of consolidation

Void ratio

Initial void ratio

$e_{0}$ at the $j$ th nodal point

Void ratio corresponding to the vertical effective stress $\sigma_{\mathrm{v} 1}^{\prime}$ on the normal compression line

Void ratio $e$ at depth $x_{j}$ and time $T_{\mathrm{v} k}$

The final void ratio at depth $x_{j}$

Void ratio corresponding to preconsolidation vertical effective stress $\sigma_{\mathrm{vpc}}^{\prime}$ on the normal compression line $e_{\mathrm{pc}}$ at the $j$ th nodal point Specific gravity of clay particles Initial thickness of the clay layer Lagrangian coordinate of the flow front at time $t$

$R:$

$S_{\mathrm{pc}}$ :

$S_{\mathrm{pcj} j}$ :

$S_{t}$ :

$S_{\infty}:$

$T_{j}$ :

$T_{\mathrm{v}}$ :

$T_{\mathrm{vc}}$ :

$T_{\mathrm{v} k}$ :

$t:$

$U_{\mathrm{pt}}$ :
Hydraulic gradient

Threshold hydraulic gradient

Coefficient of volume compressibility

Total number of equal thin layers divided in the spatial domain

A dimensionless parameter, $Q=q(t) / \sigma_{\mathrm{v} 1}^{\prime}$ A dimensionless parameter, $Q^{0}=q^{0} / \sigma_{\mathrm{v} 1}^{\prime}$ $Q$ at time $T_{\mathrm{v} k}$

A dimensionless parameter, $Q^{u}=q_{c} / \sigma_{\mathrm{vl}}^{\prime}$ Initial magnitude of time-dependent load

$q_{\mathrm{c}}$ : $\quad$ Ultimate magnitude of time-dependent load

$q(t): \quad$ Time-dependent load

A dimensionless parameter,

$R=i_{0} \gamma_{\mathrm{w}} H / \sigma_{\mathrm{v} 1}^{\prime}$

$S: \quad$ A dimensionless parameter, $S=\sigma_{\mathrm{v} 0}^{\prime} / \sigma_{\mathrm{v} 1}^{\prime}$

$S_{j}: \quad S$ at the $j$ th nodal point

$\Delta T_{\mathrm{vk}}:$

A dimensionless parameter, $S_{\mathrm{pc}}=\sigma_{\mathrm{vpc}}^{\prime} / \sigma_{\mathrm{v} 1}^{\prime}$ $S_{\mathrm{pc}}$ at the $j$ th nodal point

The settlement of the clay layer at time $t$ The final settlement of the clay layer Time for the moving flow front to reach $x_{j}$ Dimensionless time factor, $T_{\mathrm{v}}=c_{\mathrm{v} 1} t / H^{2}$ Dimensionless time factor corresponding to $t_{\mathrm{c}}, T_{\mathrm{vc}}=c_{\mathrm{v} 1} t_{\mathrm{c}} / H^{2}$

The final time of the $k$ th time interval The $k$ th time interval

Time

Time of establishment for the timedependent load

$U: \quad$ A dimensionless parameter, $U=u / \sigma_{\mathrm{vl}}^{\prime}$

$U_{j}^{k}: \quad U$ at depth $x_{j}$ and time $T_{\mathrm{v} k}$

$U_{j}^{\infty}$ : $\quad$ Residual excess pore water pressure
Average degree of consolidation in terms of excess pore water pressure 


$\begin{array}{ll}U_{\mathrm{st}}: & \begin{array}{l}\text { Average degree of consolidation in terms } \\ \text { of deformation }\end{array} \\ u: & \text { Excess pore water pressure } \\ v: & \text { Velocity of water flow } \\ X: & \text { A dimensionless parameter, } X=h(t) / H \\ x: & \text { A dimensionless parameter, } x=a / H \\ x_{j}: & x \text { at the jth nodal point } \\ \Delta x: & \text { Dimensionless value of the thickness of } \\ & \text { each thin layer. }\end{array}$

\section{Data Availability}

The data used to support the findings of this study are available from the corresponding author upon request.

\section{Conflicts of Interest}

The authors declare no conflicts of interest.

\section{Acknowledgments}

This research was supported by the National Natural Science Foundation of China (No. 51878320). This support is gratefully acknowledged.

\section{References}

[1] J. E. Garlanger, "The consolidation of soils exhibiting creep under constant effective stress," Géotechnique, vol. 22, no. 1, pp. 71-78, 1972.

[2] G. Mesri, "Theory of consolidation for clays," Journal of the Soil Mechanics and Foundation Division, vol. 100, no. 8, pp. 889-904, 1974.

[3] K. H. Xie, J. B. Wen, H. W. Ying, and A. F. Hu, "Onedimensional consolidation theory of double-layered soil considering effects of stress history," Journal of Zhejiang University (Engineering Science), vol. 41, pp. 1126-1131, 2007, in Chinese.

[4] J. L. Qiu, H. Q. Liu, J. X. Lai, H. P. Lai, J. X. Chen, and K. Wang, "Investigating the long term settlement of a tunnel built over improved loessial foundation soil using jet grouting technique," Journal of Performance of Constructed Facilities, vol. 32, no. 5, article 04018066, 2018.

[5] Y. Watabe and S. Leroueil, "Modeling and implementation of the isotache concept for long-term consolidation behavior," International Journal of Geomechanics, vol. 15, no. 5, article A4014006, 2015.

[6] M. R. Karim, F. Oka, K. Krabbenhoft, S. Leroueil, and S. Kimoto, "Simulation of long-term consolidation behavior of soft sensitive clay using an elasto-viscoplastic constitutive model," International Journal for Numerical \& Analytical Methods in Geomechanics, vol. 37, no. 16, pp. 2801-2824, 2013.

[7] H. Wu, L. Hu, W. Qi, and Q. Wen, "Analytical solution for electroosmotic consolidation considering nonlinear variation of soil parameters," International Journal of Geomechanics, vol. 17, no. 5, article 06016032, 2016.

[8] M. D. Liu and J. P. Carter, "Volumetric deformation of natural clays," International Journal of Geomechanics, vol. 3, no. 2, pp. 236-252, 2003.

[9] K. Terzaghi, Theoretical Clay Mechanics, Wiley, New York, NY, USA, 1943.
[10] D. Swartzendruber, "Modification of Darcy's law for the flow of water in soils," Soil Science, vol. 93, no. 1, pp. 22-29, 1962.

[11] R. J. Miller and P. F. Low, "Threshold gradient for water flow in clay systems1," Soil Science Society of America Journal, vol. 27, no. 6, pp. 605-609, 1963.

[12] H. W. Olsen, "Osmosis: a cause of apparent deviations from Darcy's law,” Canadian Geotechnical Journal, vol. 22, no. 2, pp. 238-241, 1985.

[13] S. Hansbo, "Aspects of vertical drain design: Darcian or nonDarcian flow,” Géotechnique, vol. 47, no. 5, pp. 983-992, 1997.

[14] S. Hansbo, "Deviation from Darcy's law observed in onedimensional consolidation," Géotechnique, vol. 53, no. 6, pp. 601-605, 2003.

[15] J. Mitchell and J. Younger, Abnormalities in Hydraulic Flow through Fine-Grained Soils: ASTM Special Publication, Vol. 417, American Society for Testing and Materials, Philadelphia, PA, USA, 1967.

[16] F. Pascal, H. Pascal, and D. W. Murray, "Consolidation with threshold gradients," International Journal for Numerical and Analytical Methods in Geomechanics, vol. 5, no. 3, pp. 247261, 1981.

[17] K.-H. Xie, K. Wang, Y.-L. Wang, and C.-X. Li, “Analytical solution for one-dimensional consolidation of clayey soils with a threshold gradient," Computers and Geotechnics, vol. 37, no. 4, pp. 487-493, 2010.

[18] Y. Zhou, W. K. Bu, and M. M. Lu, "One-dimensional consolidation with a threshold gradient: a Stefan problem with rate-dependent latent heat," International Journal for $\mathrm{Nu}$ merical \& Analytical Methods in Geomechanics, vol. 37, no. 16, pp. 2825-2832, 2013.

[19] X. Guo, K. H. Xie, and Y. B. Deng, "Consolidation by prefabricated vertical drains with a threshold gradient," Mathematical Problems In Engineering, vol. 2014, Article ID 410390, 9 pages, 2014.

[20] J. Yao, W. Liu, and Z. Chen, "Numerical solution of a moving boundary problem of one-dimensional flow in semi-infinite long porous media with threshold pressure gradient," Mathematical Problems in Engineering, vol. 2013, Article ID 384246, 7 pages, 2013.

[21] R. E. Gibson, R. L. Schiffman, and K. W. Cargill, "The theory of one-dimensional consolidation of saturated clays. II. Finite nonlinear consolidation of thick homogeneous layers," Canadian Geotechnical Journal, vol. 18, no. 2, pp. 280-293, 1981.

[22] K. W. Cargill, "Prediction of consolidation of very soft soil," Journal of Geotechnical Engineering, vol. 110, no. 6, pp. 775-795, 1984.

[23] M. B. Chopra and G. F. Dargush, "Finite-element analysis of time-dependent large-deformation problems," International Journal for Numerical and Analytical Methods in Geomechanics, vol. 16, no. 2, pp. 101-130, 1992.

[24] P. H. Morris, "Analytical solutions of linear finite-strain onedimensional consolidation," Journal of Geotechnical and Geoenvironmental Engineering, vol. 128, no. 4, pp. 319-326, 2002.

[25] T. Tan and R. F. Scott, "Finite strain consolidation-a study of convection," Soils and Foundations, vol. 28, no. 3, pp. 64-74, 1988.

[26] K. H. Xie and C. J. Leo, "Analytical solutions of onedimensional large strain consolidation of saturated and homogeneous clays," Computers and Geotechnics, vol. 31, no. 4, pp. 301-314, 2004. 
[27] D. P. Simon and C. Viggiani, "Settlelment of a thick bed of normally consolidated uniform clay," Géotechnique, vol. 25, no. 2, pp. 390-393, 1975.

[28] C.-x. Li and K.-h. Xie, "One-dimensional nonlinear consolidation of soft clay with the non-Darcian flow," Journal of Zhejiang University Science A, vol. 14, no. 6, pp. 435-446, 2013.

[29] C.-x. Li, C.-j. Wang, M.-m. Lu, J.-f. Lu, and K.-h. Xie, "Onedimensional large-strain consolidation of soft clay with nonDarcian flow and nonlinear compression and permeability of soil," Journal of Central South University, vol. 24, no. 4, pp. 967-976, 2017, in Chinese. 


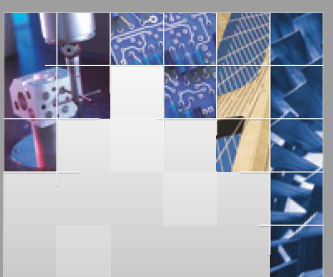

\section{Enfincering}
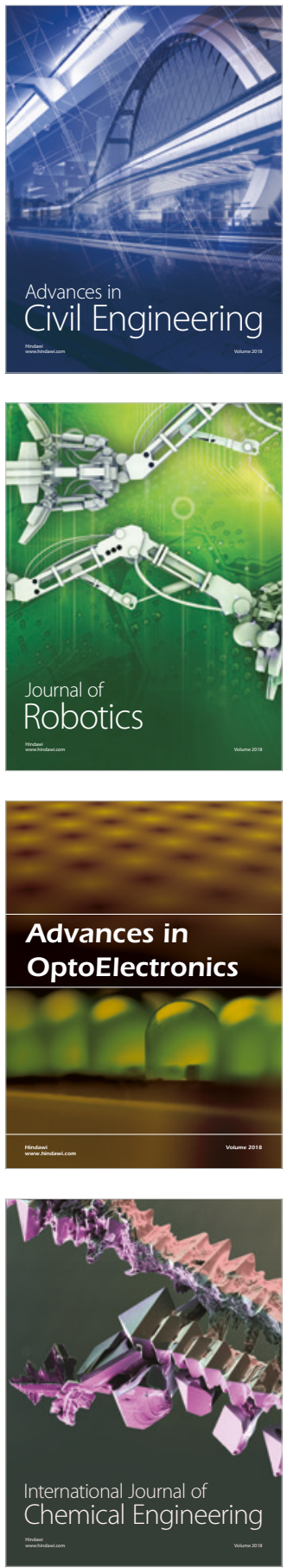

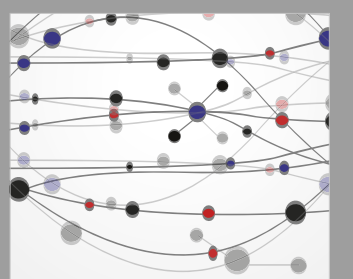

\section{Rotating \\ Machinery}

The Scientific World Journal

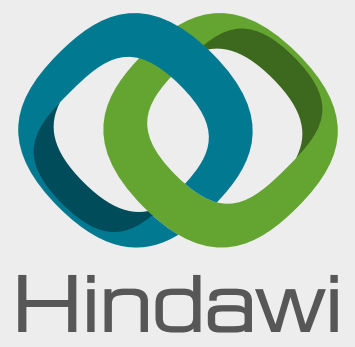

Submit your manuscripts at

www.hindawi.com
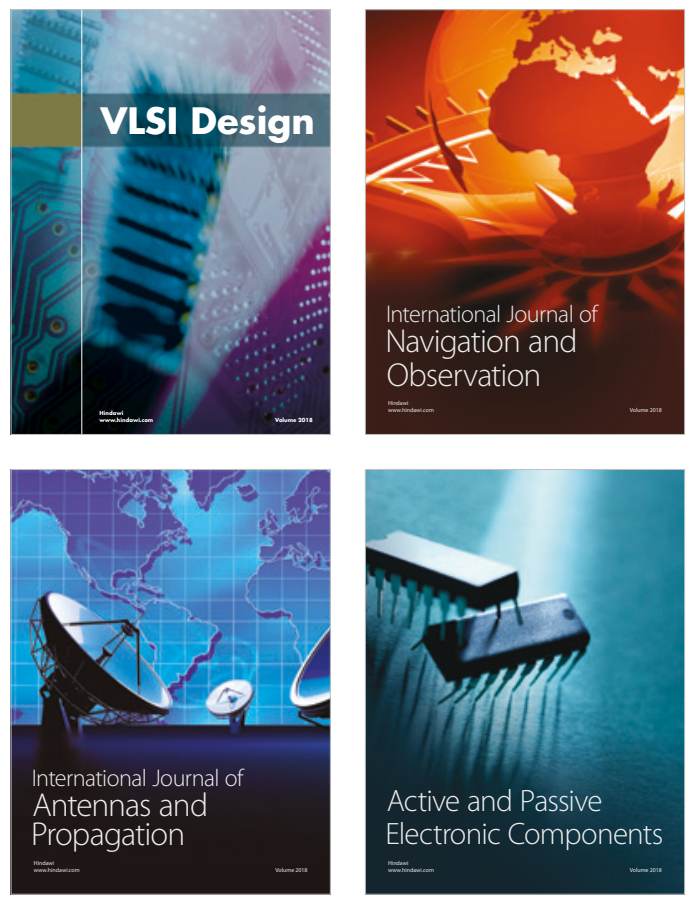
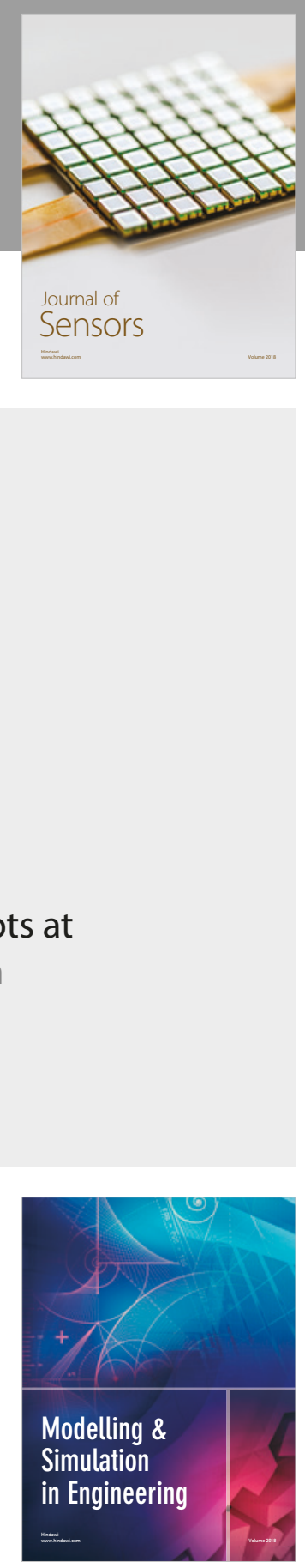

\section{Advances \\ Multimedia}
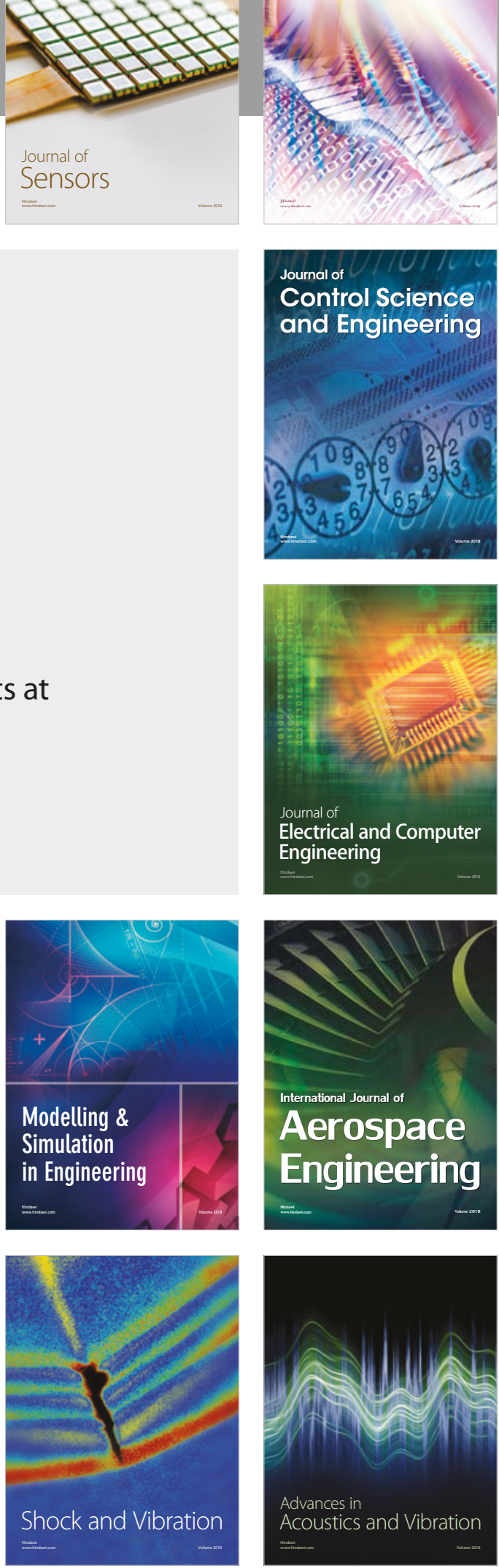